\title{
Should Monetary Policy Target Financial Stability?
}

\author{
William Chen* Gregory Phelan ${ }^{\dagger}$
}

This version: November 4, 2020

\begin{abstract}
Monetary policy can promote financial stability and improve household welfare. We consider a macro model with a financial sector in which banks do not actively issue equity, output and growth depend on the aggregate level of bank equity, and equilibrium is inefficient. Monetary policy rules responding to the financial sector are ex-ante stabilizing because their effects on risk premia decrease the likelihood of crises and boost leverage during downturns. Stability gains from monetary policy increase welfare whenever macroprudential policy is poorly targeted. If macroprudential policy is sufficiently well-targeted to promote financial stability, then monetary policy should not target financial stability.
\end{abstract}

Keywords: Monetary policy, Leaning against the wind, Financial stability, Macroeconomic instability, Macroprudential policy, Banks, Liquidity.

JEL classification: E44, E52, E58, G01, G12, G20, G21.

*Williams College. Email: wyc1@williams.edu

${ }^{\dagger}$ Department of Economics, Williams College. Email: gp4@williams.edu.

Website: https://sites.google.com/site/gregoryphelan/.

We are grateful for feedback from Marco Del Negro, Fernando Duarte, Jesús Fernández-Villaverde, Simon Gilchrist, and Alejandro Van der Ghote, and from seminar participants at the Federal Reserve Bank of New York and the Darden School of Business at the University of Virginia. The errors are our own. 


\section{Introduction}

Economists increasingly debate whether monetary policy should be used to stabilize the financial system. It is widely recognized that central bankers may pursue aggressive policies to stabilize the financial system during downturns-i.e., enacting a "Fed Put" to cut borrowing costs—which encourages excessive risk-taking and leverage in good times and may ex-ante increase the probability of financial crises. To counteract excessive risk-taking, some economists suggest that central banks should "lean against the wind" ("LAW") in good times to mitigate overheating in the the financial sector. Proponents argue that systematically raising the cost of intermediation in good times will decrease the probability of (extremely costly) financial crises. 1.1 There are prevailing doubts that the benefits of LAW outweigh the costs, and LAW may exacerbate crises if the economy enters a crisis starting from a weaker position (Svensson, 2017).

Core to this debate is whether the financial sector creates inefficiencies with aggregate consequences that monetary policy can adequately address. Monetary policy should consider targeting financial conditions in addition to (or independent of) conventional targets only if the financial sector creates additional externalities. In other words, to justify targeting financial stability in addition to inflation or output gaps, the financial sector must be more than a source of shocks to the rest of the economy; it must be an inefficient source of shocks..$^{2}$ This raises several fundamental questions. How do monetary policy rules affect financial stability? Can monetary policy effectively correct financial-sector externalities? Do any benefits of targeting financial stability with monetary policy persist if macroprudential tools are available?

We answer these questions using a continuous-time stochastic general equilibrium model in which financial frictions endogenously create inefficient instability and systemic risk, building on Brunnermeier and Sannikov (2014). Banks invest in productive capital, but banks can issue only risk-free debt and not equity. As a result, banks invest more when they have more equity, and capital is allocated more efficiently when banks are well-capitalized. Limited equity issuance

\footnotetext{
${ }^{1}$ See BIS (2014, 2016), Borio (2014); Borio et al. (2018) and Juselius et al. (2017). See also Adrian and Liang (2016); Adrian and Duarte (2016); Adrian et al. (2019).

${ }^{2}$ If there were no externalities, then targeting the output gap in general would also indirectly address output gaps caused by shocks to the financial sector; financial-sector shocks would just be demand or supply shocks to respond to in the usual way.
} 
creates a distortion between the private and social values of bank equity, and so policies that improve financial stability can potentially increase household welfare. To this setting we add the model of monetary policy transmission from Drechsler et al. (2018) in which the nominal interest rate determines the liquidity premium on banks' investments. We assess optimal monetary policy and explain the underlying mechanisms by investigating the impact of interest rate rules on the amplification of shocks, nonlinear dynamics, and systemic risk, which are central features of the framework in Brunnermeier and Sannikov (2014). We then evaluate whether macroprudential policy in the form of state-contingent leverage constraints changes the optimal monetary policy.

In our model, monetary policy can affect the return on banks' investments, the rate of bank equity growth, and banks' leverage decisions. Through these effects, monetary policy can change the frequency and duration of good and bad outcomes. We solve for the global dynamics of the economy and find that the impact of interest rate rules on bank profitability, and thus on bank equity growth, varies systematically with the state of the economy. How bank leverage varies over the financial cycle depends primarily on how monetary policy changes over the cycle, much more than on the overall level of rates.

Optimal monetary policy combines a Fed Put with LAW because it increases financial stability ex-ante. A Fed Put increases leverage in bad times, which improves aggregate outcomes and raises the expected rate at which banks recapitalize during crises. Surprisingly, even though banks expect accommodation during crises, bank leverage in good times and asset price volatility do not sharply increase, so the probability of crises is ex-ante lower with a Fed Put. LAW further improves financial stability. Because the effects of monetary policy on leverage, asset price volatility, and stability are state-dependent, the timing of interest rate movements matters. A large rate cut can stabilize the financial sector better than a series of shallow rate cuts that start "early."

Many economists have argued that macroprudential policy (MaP) should be the main tool for addressing financial crises (see Svensson, 2017). An important concern is whether monetary policy still improves financial stability and/or welfare when macroprudential policy has been applied. We find that if macroprudential policy is poorly targeted, then monetary policy should continue to address financial stability, and conversely, if macroprudential tools are well-targeted, then mone- 
tary policy should not address financial stability. When macroprudential policy does not restrict leverage at the right times, monetary policy has scope to improve stability and welfare. However, if macroprudential tools properly target excessive risk taking across the financial cycle, then monetary policy is free to focus on conventional targets (e.g. inflation).

Related Literature Methodologically, our paper follows the stochastic continuous-time macro literature, pioneered by Brunnermeier and Sannikov (2014, 2015, 2016a) and He and Krishnamurthy (2012, 2013, 2019), who analyze the nonlinear global dynamics of economies with financial frictions, building on seminal results from Kiyotaki and Moore (1997) and Bernanke et al. (1999). Within this literature, we combine the models of Drechsler et al. (2018) and Phelan (2016) to study how monetary policy affects global dynamics. Drechsler et al. (2018) develop a dynamic asset pricing model in which banks hold liquidity buffers to insure deposits against funding risks. By influencing the liquidity premium on deposits, monetary policy affects the risk premium component of the cost of capital. Risk-tolerant agents take deposits from risk-averse agents to buy assets, and lower nominal rates raise leverage, resulting in lower risk premia as well as higher asset prices and volatility $\left.\right|^{3}$ We find that monetary policy has different effects on stability depending on the extent to which the returns on productive factors are affected.

It is helpful to contrast our results with several closely-related papers. Svensson (2017) assumes that a weaker economy in good times leads to a weaker economy in a crisis. This generally need not be the case in reality, and in our model a Fed Put leads to a less severe crisis because bank leverage increases in a crisis, a feature that is shared by Caballero and Simsek $(2019,2020)$. These latter papers study the role of monetary and macroprudential policies to mitigate the severity of demand-driven recessions. However, in these papers while the severity of a crisis is endogenous, the probability is exogenous, whereas in our model both the severity and likelihood of crises are endogenous. Van der Ghote (2020) shows that in a New Keynesian version of the model in Brunnermeier and Sannikov (2014), it is optimal for monetary policy to implement a countercyclical

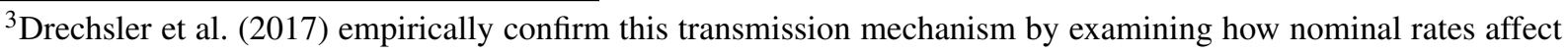
the supply of retail bank deposits, an important class of liquid assets. Bernanke and Kuttner (2005) document empirically that monetary policy shocks decrease risk premia. Kekre and Lenel (2019) consider a New Keynesian model in which monetary policy shocks lower risk premia by redistributing wealth toward agents with greater propensities to invest in risky capital.
} 
employment gap. In that model, monetary policy affects banks' risk-taking incentives only indirectly through the impact of the nominal rate on price dispersion. In current work, Van der Ghote (2019) includes money as a means of payments to examine the real effects of interest-rate corridor policies, which affect the cost of liquidity in financial markets.

There is a broad literature studying the relationship between monetary policy and financial stability. Cieslak and Vissing-Jorgensen (2020) find that the Federal funds rate responds to asset prices (the stock market); we consider responses to the condition of the financial sector specifically (banks' equity levels). Several papers have cautioned against central banks intervening in financial markets (Diamond and Rajan, 2012; Farhi and Tirole, 2012). We take maturity mismatch and correlated risks as given and then consider, given these features, how monetary policy affects stability. Because of the general equilibrium effects in our model, a Fed Put increases leverage when rates are low but not before and the increase in leverage in bad times is stabilizing. Moreover, a Put does not introduce a commitment or time-consistency problem because it is ex-ante stabilizing. These results add to the analysis of Bornstein and Lorenzoni (2018), who develop a simple model where passive monetary policy causes overborrowing due to an aggregate demand externality. Our model suggests that moral hazard may not be a concern when a Fed Put addresses resource misallocation.

Our paper's insight is also distinct from other research affirming the use of monetary policy to address financial stability. Stein (2012) provides a model in which monetary policy can enhance financial stability by reducing excessive short-term debt. Gertler and Karadi (2011), Cúrdia and Woodford (2011, 2016), Christiano et al. (2015), and Caballero and Simsek (2019) study the ability of monetary policy to address aggregate demand externalities in models with financial frictions, and show that prudential monetary policy can mitigate the severity of a demand-driven recession. In our economy, monetary policy corrects a pecuniary externality that produces dynamic resource misallocation affecting both the severity and the probability of crises. These results together show monetary policy can mitigate aggregate demand and aggregate supply issues caused by financial frictions. Hansen (2018) characterizes LQ-optimal monetary policy near an efficient deterministic steady state in a New Keynesian economy with a Bernanke and Gertler (1989) financial accelerator. Equilibrium in our model is inefficient with a stochastic steady state. 


\section{Model}

The economy is populated by households and banks, owned by households. Capital can be used to produce a final consumption good, which can be re-invested to create new capital. Banks have an advantage at producing the consumption good. As a result, output and growth depend endogenously on capital ownership. The financial friction is costly equity issuance. Outcomes will depend on the level of equity in the banking sector. The model combines elements of the models in Brunnermeier and Sannikov (2014), Phelan (2016), and Drechsler et al. (2018).

The baseline model presented in this section does not include macroprudential policy. Section 4 introduces macroprudential policy (leverage limits) and considers the interaction between macroprudential and monetary policy rules. Proofs are given in Appendix A.

\subsection{Technology, Environment, and Markets}

Time is continuous and infinite, and aggregate productivity shocks follow a Wiener process.

Capital The effective capital quantity $k_{t}$ evolves according to equation (1),

$$
\frac{d k_{t}}{k_{t}}=\left(\Phi\left(\boldsymbol{l}_{t}\right)-\delta\right) d t+\sigma d W_{t}
$$

where $\Phi(\cdot)$ is a standard investment technology, $\iota$ is the rate of internal investment, $\sigma$ is the volatility of capital growth, and $W_{t}$ is an exogenous standard Brownian motion. The technology $\Phi(\cdot)$ satisfies $\Phi(0)=0, \Phi^{\prime}(0)=1, \Phi^{\prime}(\cdot)>0$, and $\Phi^{\prime \prime}(\cdot)<0$. In equilibrium, $\boldsymbol{l}_{t}$ is the same for banks and households. To reduce notation, we directly use this result when writing the growth rate.

Capital can be used to produce the final consumption good. Banks produce consumption goods at the rate $a_{b} k_{t}$ while households produce at the rate $a_{h} k_{t}$, where $a_{b}>a_{h}$.

Capital is traded in a perfectly competitive market at a real price $Q_{t}$. We postulate that the real capital price (the "asset price") follows the process

$$
\frac{d Q_{t}}{Q_{t}}=\mu_{Q, t} d t+\sigma_{Q, t} d W_{t}
$$


which will be determined endogenously in equilibrium. The return to owning capital includes dividends from production and the capital gains on the value of the capital. By Ito's Lemma, the real rate of return to agent $i$ using capital is

$$
d r_{t}^{i}=\left(\frac{a_{i}-\imath_{t}}{Q_{t}}+\Phi\left(\imath_{t}\right)-\delta+\mu_{Q, t}+\sigma \sigma_{Q, t}\right) d t+\left(\sigma+\sigma_{Q, t}\right) d W_{t}
$$

The volatility of returns on investments is $\sigma+\sigma_{Q, t}$, which includes fundamental risk $\sigma$ and endogenous price risk $\sigma_{Q, t}$.

Deposits and Monetary Policy There is a market for risk-free deposits. Deposits are in zero netsupply with endogenous real return $d r_{f, t}$, which we assume has paths of finite variation. The central bank sets the nominal interest rate $i_{t}$ on deposits. (See Appendix B for details on implementation.) Inflation is determined according to a standard Fisher equation

$$
i_{t}=d r_{f, t}+\pi_{t}
$$

We define policy functions for $i_{t}$ later. We assume inflation is locally deterministic, i.e. $\frac{d p_{t}}{p_{t}}=\pi_{t} d t$.

Within the framework of our model, monetary policy is said to "target financial stability" when the nominal interest rate deviates from some baseline path. A straightforward baseline is a constant nominal rate. A constant nominal rate implies that monetary policy never responds to the state of the financial sector, so it does not treat financial stability as a target. In the absence of nominal rigidities but with liquidity costs imposed by nominal rates, ignoring the financial sector would mean following the Friedman Rule (see also Proposition 4).

\subsection{Households, Banks, and Asset Pricing}

There is a continuum of risk-averse households denoted by $h \in[0,1]$ with initial wealths $n_{h, 0}$. Lifetime utility is given by

$$
V_{\tau}=\mathbb{E}_{\tau}\left[\int_{\tau}^{\infty} e^{-r(t-\tau)} \log \left(c_{h, t}\right) d t\right]
$$


where $c_{h, t}$ is household flow consumption and $r$ is the discount rate.

There is a continuum of banks, denoted by $b \in[0,1]$, with initial book value ("equity") $n_{b, 0}$. Banks invest in capital and issue deposits. Banks are owned by households, who choose dividend payouts, the level of deposits, the level of liquid reserves, and the portfolio weight on capital used by banks. Because of un-modeled financial frictions, banks are subject to two constraints. First, equity issuance is infinitely costly (i.e., dividends must be positive). Second, the value of banks' assets minus liabilities $n_{b, t}$ cannot become negative (bankruptcy).

Banks maximize the present value of dividends subject to their constraints. Dividends are discounted by households' stochastic discount factor $\xi_{t}$. Since households have log utility, the stochastic discount factor is $\xi_{t}=e^{-r t} c_{h, t}^{-1}$. Due to banks' productivity advantage, banks will borrow debt to hold capital. To avoid bankruptcy, they will never finance their portfolio with only debt.

Following Drechsler et al. (2018) we assume deposits are subject to funding shocks, requiring banks to self-insure by holding liquid assets. Since this behavior is not frictionless, borrowing with deposits imposes a "liquidity premium" of operations that is proportional to the nominal interest rate. See Appendix B for details.

Our results do not rely on this specific microfoundation for how monetary policy affects liquidity premia, but only need a mechanism with two properties. First, the nominal interest rate creates a wedge in banks' first-order condition for their portfolio weight on capital but not in households' first-order condition. Second, the wedge increases with the level of the nominal interest rate. Other microfoundations would imply similar results. Nominal interest rates may determine liquidity premia because banks have market power in the deposit market (see Drechsler et al., 2017; Brunnermeier and Koby, 2018), because the central bank operates monetary policy through a corridor system ${ }^{5}$ and open market operations (see Bigio and Sannikov, 2019; Van der Ghote, 2019),

\footnotetext{
${ }^{4}$ The assumption that bank equity is "sticky" is empirically supported by Acharya et al. (2011), which shows that the capital raised by banks during the crisis was almost entirely in the form of debt and preferred stock and not in the form of common equity. Adrian and Shin (2010, 2011) provide evidence that the predetermined balance sheet variable for banks and other financial banks is equity, not assets. Our results generalize so long as banks do not issue equity too frequently. Relatedly, Gambacorta and Shin (2016) provide evidence that bank capital matters for monetary policy transmission.

${ }^{5}$ While the Federal Reserve has used a floor system since 2008, many central banks (e.g. the Riksbank) continue to operate corridor systems. Therefore, modeling monetary policy implementation as a corridor system still has empirical relevance.
} 
or because banks use short bonds as collateral to back inside money (Lenel et al., 2019).

Households' Problem Each household owns a bank, so their wealth $w_{h, t}$ equals the sum of their "personal net worth" $n_{h, t}$ and the value of the shares in bank equity $U_{t}$. The distinction between $n_{h, t}$ and $U_{t}$ is necessary because banks control dividend payouts and cannot issue equity. Aggregate investment into bank equity is not determined by households, but household wealth also includes capital holdings and bank deposits, which households do control. Personal net worth refers to these latter quantities. It will be useful to define $\omega_{t} \equiv n_{h, t} / w_{h, t}$, which is the share of a household's total wealth that is held in their personal net worth.

Let $\left(x_{h, t}, x_{h d, t}\right)$ be household's portfolio weight on capital and debt, respectively. Since the weights must sum to one, rewrite $x_{h d, t}=1-x_{h, t}$. Formally, households solve the problem

$$
\max _{x_{h, t} \geq 0, c_{h, t}, l_{t}} \mathbb{E}_{\tau}\left[\int_{\tau}^{\infty} e^{-r(t-\tau)} \log \left(c_{h, t}\right) d t\right]
$$

subject to

$$
\begin{aligned}
& \frac{d n_{h, t}}{n_{h, t}}=d r_{f, t}+x_{h, t}\left(d r_{t}^{h}-d r_{f, t}\right)+\left(\mathscr{T}_{t}-\frac{c_{h, t}}{n_{h, t}}\right) d t \\
& n_{h, t}, x_{h, t} \geq 0 .
\end{aligned}
$$

where $\mathscr{T}_{t}$ denotes all transfers received by households normalized by their personal net worth. Transfers include dividends from banks and any payouts from the government.

Proposition 1 characterizes households' optimal decisions.

Proposition 1. Let $\sigma_{c h, t}$ denote the volatility of a household's consumption. Then households choose $x_{h, t}$ and $c_{h, t}$ such that $(i) \mathbb{E}\left[d r_{t}^{h}\right]-d r_{f, t} \leq \sigma_{c h, t}\left(\sigma+\sigma_{Q, t}\right)$, and the inequality binds if and only if $x_{h, t}>0$; (ii) $c_{h, t}=r\left(n_{h, t}+U_{t}\right)$; (iii) $\sigma_{c h, t}=\omega_{t} \sigma_{n h, t}+\left(1-\omega_{t}\right) \sigma_{U, t}$.

Households hold positive quantities of capital if the expected excess returns equal the covariance of their consumption with returns and consume a constant fraction $r$ of their total wealth. Because household consumption is proportional to their wealth, the volatility of their consumption 
can also be written as a convex combination of the volatilities of their personal net worth and the value of their bank shares.

Banks' Problem Let $\left(x_{b, t}, x_{b d, t}\right)$ be the portfolio weights on capital and debt, respectively. Since the weights must sum to one, we rewrite $x_{d b, t}=1-x_{b, t}$. Formally, banks solve the problem

$$
\max _{x_{b, t} \geq 0, d \zeta_{t} \geq 0, l_{t}} U_{\tau}=\mathbb{E}_{\tau}\left[\int_{\tau}^{\infty} \frac{\xi_{t}}{\xi_{\tau}} d \zeta_{t}\right],
$$

subject to

$$
\begin{aligned}
& \frac{d n_{b, t}}{n_{b, t}}=d r_{f, t}-\left(\left(x_{b, t}-1\right) \gamma i_{t}+T_{t}\right) d t+x_{b, t}\left(d r_{t}^{b}-d r_{f, t}\right)-\frac{d \zeta_{t}}{n_{b, t}} \\
& n_{b, t}, x_{b, t}, d \zeta_{t} \geq 0 .
\end{aligned}
$$

Banks earn the deposit rate, pay the liquidity premium from holding reserves to back deposits, earn the risk premium on capital holdings, and pay dividends at rate $d \zeta_{t} .6$ They also pay a tax $T_{t}$, which we include as a model technique to ensure a nondegenerate stationary distribution: 7 The tax is lump-sum distributed to households.

By homogeneity and price-taking, we can write the maximized value of a bank with equity $n_{b, t}$ as

$$
\theta_{\tau} n_{b, \tau} \equiv \max _{x_{b, t} \geq 0, d \zeta_{t} \geq 0, l_{t}} \mathbb{E}_{\tau}\left[\int_{\tau}^{\infty} \frac{\xi_{t}}{\xi_{\tau}} d \zeta_{t}\right]
$$

where $\theta_{t}$ is the marginal value of equity, which summarizes how market conditions affect the value of the bank per dollar of equity. The value $\theta_{t}$ equals 1 plus the multiplier on the equity-issuance constraint and reflects the aggregate condition of the financial sector.

We can further characterize the optimality conditions in the following way.

\footnotetext{
${ }^{6}$ To minimize notation, we write banks' problem after substituting their first-order condition for the portfolio weight on reserves. Let $x_{M, t}$ be the weight on reserves. The microfoundation for monetary policy from Drechsler et al. (2018) implies $x_{M, t}=-\gamma x_{b d, t}=\gamma\left(x_{b, t}-1\right)$. In general, this formulation of the bank problem is correct as long as the microfoundation implies that a bank scales its holdings of reserves in proportion to the level of its deposits.

${ }^{7}$ Alternative schemes to ensure a nondegenerate distribution include exogenous retirement, a preference for bank debt in household's utility function, and assuming banks are more impatient because they discount dividends using $e^{-r_{b} t} \xi_{t}$, where $r_{b}>0$. An earlier version of the paper used a preference for bank debt in household's utility function and the results are qualitatively the same.
} 
Proposition 2. Assume $\theta_{t}$ and $c_{h, t}$ follow the finite diffusions

$$
\begin{array}{r}
\frac{d \theta_{t}}{\theta_{t}}=\mu_{\theta, t} d t+\sigma_{\theta, t} d W_{t}, \\
\frac{d c_{h, t}}{c_{h, t}}=\mu_{c h, t} d t+\sigma_{c h, t} d W_{t},
\end{array}
$$

with $\sigma_{\theta, t} \leq 0$. Then $\theta_{t} n_{t}$ represents the maximal future expected payoff that a bank with book value $n_{t}$ can attain, and $\left\{x_{b, t}, d \zeta_{t}, l_{t}\right\}$ is optimal if and only if (i) $\theta_{t} \geq 1 \forall t$, (ii) $d \zeta_{t}>0$ only when $\theta_{t}=1$, and $d \zeta_{t}=0$ otherwise, (iii) $\mu_{\theta, t}=T_{t}+\sigma_{c h, t} \sigma_{\theta, t}-\gamma i_{t}$, (iv) $\mathbb{E}\left[d r_{t}^{b}\right]-d r_{f, t}-L P_{t} \leq$ $\left(\sigma_{c h, t}-\sigma_{\theta, t}\right)\left(\sigma+\sigma_{Q, t}\right)$, with strict equality when $x_{b, t}>0,(v) \Phi^{\prime}\left(\boldsymbol{l}_{t}\right)=1 / Q_{t}$, (vi) The transversality condition $\mathbb{E}\left[\xi_{t} \theta_{t} n_{t}\right] \rightarrow 0$ holds under $\left\{x_{b, t}, d \zeta_{t}\right\}$.

These optimality conditions provide insight about equilibrium dynamics. Banks will not pay dividends when $\theta_{t} \geq 1 ; \theta_{t}$ can never be less than one because banks can always pay out the full value of equity, guaranteeing a value of at least $n_{b, t}$. Define the excess risk premium $E R P_{t} \equiv$ $-\sigma_{\theta, t}\left(\sigma+\sigma_{Q, t}\right)$ and the liquidity premium $L P_{t} \equiv \gamma i_{t}$. The excess risk premium represents banks' required risk premium (or instantaneous level of risk aversion) in excess of households' required risk premium on capital. Banks will hold capital only if the expected excess return over $L P_{t}$ is at least the sum of $E R P_{t}$ and households' risk premium. Internal investment is determined by Tobin's q. Finally, cutting interest rates locally affects the marginal value of bank equity by increasing the drift of $\theta_{t}$. Whenever $\mu_{\theta, t}<0$, lower rates slow down the expected decrease in $\theta_{t}$, and whenever $\mu_{\theta, t}>0$, lower rates accelerate the expected increase in $\theta_{t}$.

Asset Pricing Since we look for an equilibrium where the risk premium and liquidity premium are both non-negative, banks will almost surely hold capital. Banks' first-order condition for their portfolio weight on capital implies

$$
\frac{a_{b}-\imath_{t}}{Q_{t}}+\Phi\left(\imath_{t}\right)-\delta+\mu_{Q, t}+\sigma \sigma_{Q, t}=d r_{f, t}+\sigma_{c h, t}\left(\sigma+\sigma_{Q, t}\right)+E R P_{t}+L P_{t}
$$


Households choose capital so that

$$
\frac{a_{h}-\imath_{t}}{Q_{t}}+\Phi\left(\boldsymbol{l}_{t}\right)-\delta+\mu_{Q, t}+\sigma \sigma_{Q, t} \leq d r_{f, t}+\sigma_{c h, t}\left(\sigma+\sigma_{Q, t}\right)
$$

where the inequality reflects that households may not always hold capital in equilibrium. Differencing (10) and (11) yields the equilibrium asset pricing condition:

$$
\frac{a_{b}-a_{h}}{Q_{t}} \geq E R P_{t}+L P_{t}
$$

Relative to households, banks earn extra returns of at least $E R P_{t}+L P_{t}$ because they have higher productivity but also bear the risk of holding capital. Condition (12) binds whenever households hold a positive quantity of capital.

\subsection{Characterizing Equilibrium}

A competitive equilibrium is characterized by the market price for the risky asset, together with portfolio allocations and consumption decisions such that given prices, agents optimize and markets clear. Due to equity issuance frictions, banks' decisions depend on their level of equity, and so equilibrium depends on banks' equity levels and monetary policy has scope to affect equilibrium.

We solve for the global equilibrium dynamics using the methods in Brunnermeier and Sannikov (2014). Define $N_{b, t}=\int n_{b, t} d b$ as aggregate bank equity. Because capital grows geometrically and the bank problem is homogenous, the equilibrium state variable of interest is aggregate bank equity as a fraction of total value of capital:

$$
\eta_{t}=\frac{N_{b, t}}{Q_{t} K_{t}}
$$

Equilibrium consists of a law of motion for $\eta_{t}$, and asset allocations and prices as functions of $\eta$. The asset prices are $Q(\eta)$ and $\theta(\eta)$, and the flow allocation is the fraction of capital held by banks $\psi(\eta)$. We derive the evolution of $\eta_{t}$ using Ito's Lemma and the equations for returns and budget constraints. 
Lemma 1. The equilibrium law of motion of $\eta$ will be endogenously given as

$$
\frac{d \eta_{t}}{\eta_{t}}=\mu_{\eta, t} d t+\sigma_{\eta, t} d W_{t}+d \Xi_{t}
$$

where $d \Xi_{t}$ is an impulse variable creating a regulated diffusion. Furthermore,

$$
\begin{gathered}
\mu_{\eta, t}=\frac{a_{b}-l_{t}}{Q_{t}}-T_{t}+\left(\frac{\psi_{t}}{\eta_{t}}-1\right)\left(\left(\sigma_{c h, t}-\sigma_{\theta, t}\right)-\left(\sigma+\sigma_{Q, t}\right)\right)\left(\sigma+\sigma_{Q, t}\right)-d \Xi_{t} \\
\sigma_{\eta, t}=\left(\frac{\psi_{t}}{\eta_{t}}-1\right)\left(\sigma+\sigma_{Q, t}\right), \quad d \Xi_{t}=\frac{d \zeta_{t}}{N_{b, t}},
\end{gathered}
$$

where $d \zeta_{t}=\int d \zeta_{b, t} d b$

We convert the equilibrium conditions into a system of differential equations ("ODE") in the asset prices $Q$ and $\theta$. Given $Q(\eta), \theta(\eta)$, and $\theta^{\prime}(\eta)$ we can use equilibrium returns and allocations to derive $Q^{\prime}(\eta)$ and $\theta^{\prime \prime}(\eta)$. We solve the ODE using appropriate boundary conditions (additional details are in Appendix A.

Proposition 3. The equilibrium domain of the functions $Q(\eta), \theta(\eta)$, and $\psi(\eta)$ is an interval $\left[0, \eta^{*}\right]$. The marginal price of bank value $\theta$ is a decreasing function, and the following boundary conditions hold: (i) $\theta\left(\eta^{*}\right)=1$; (ii) $\theta^{\prime}\left(\eta^{*}\right)=0$; (iii) $Q\left(\eta^{*}\right)=\bar{Q}$; (iv) $Q^{\prime}\left(\eta^{*}\right)=0$; (v) $Q(0)=\underline{Q}$; (vi) $\lim _{\eta \rightarrow 0^{+}} \theta(\eta)=\infty$. Over $\left[0, \eta^{*}\right], \theta_{t} \geq 1$ and $d \zeta_{t}=0$, and $d \zeta_{t}>0$ at $\eta^{*}$ creating a regulated barrier for the process $\eta_{t}$. The quantity $\underline{Q}$ is the price of capital in an economy with no banks, and the quantity $\bar{Q}$ is the price of capital required by market-clearing for consumption at $\eta^{*}$.

Hence, the system ranges between 0 and $\eta^{*}$, at which point banks pay dividends because the marginal attractiveness of debt outweighs the marginal attractiveness of an additional unit of equity. When interest rates do not vary too much, there exists $\bar{\eta} \in\left(0, \eta^{*}\right)$ such that $\psi(\eta)=1$ for $\eta>\bar{\eta}$ and $\psi(\eta)<1$ for $\eta \leq \bar{\eta}]^{8}$ For high levels of $\eta$, banks can hold the entire capital stock. The evolution of $\eta$ induces a stationary density (PDF) $f(\eta)$ with $\operatorname{CDF} F(\eta)$; the density $f(\eta)$ solves a Kolmogorov-Forward equation.

\footnotetext{
${ }^{8}$ Depending on the monetary policy rule's specification, there can be multiple regions in which specialization occurs and the state space is no longer cleanly separated into two regions around a single $\bar{\eta}$. In this case, we still define stability as the measure of states when $\psi=1$.
} 
We define a crisis as when banks are so constrained that they have to sell capital at fire-sale prices to households (i.e., $\eta<\bar{\eta}$ ). The stability of the economy is the fraction of time the economy is not in a crisis:

$$
\text { Stability }=1-F(\bar{\eta}) \text {. }
$$

The fundamental problem caused by financial frictions is the inability of banks to always hold the entire capital stock. Households are worse-off when fire sales are more frequent. Our definition of stability directly quantifies this problem. While alternative measures like asset price volatility can be more easily mapped to data, our paper is primarily theoretical, so we prefer the transparency provided by our definition of stability 9 Furthermore, high volatility occurs because of fire sales. Higher stability will also imply lower asset price volatility in the long run.

If the price function is twice-continuously differentiable, then the evolutions of the capital price and marginal bank value (equations (2) and (8) ) are functions of $\eta$

$$
\frac{d Q_{t}}{Q_{t}}=\mu_{Q}\left(\eta_{t}\right) d t+\sigma_{Q}\left(\eta_{t}\right) d W_{t}, \quad \frac{d \theta_{t}}{\theta_{t}}=\mu_{\theta}\left(\eta_{t}\right) d t+\sigma_{\theta}\left(\eta_{t}\right) d W_{t}
$$

where the drift and variance terms are determined by the derivatives of $Q(\eta)$ and $\theta(\eta)$. For the remainder of the paper, we suppress the dependence on $\eta_{t}$ and on time $t$ for notational ease.

Monetary Policy Rules It is outside the scope of this paper to solve the optimal interest rate path over the space of all policy functions. We can answer the questions of interest while maintaining parsimony by focusing on a specific class of policy rules for the nominal interest rate, defined as follows:

$$
i(\eta)= \begin{cases}{ }_{i} \text { Put } & \eta<\eta^{P u t}, \\ { }_{i}^{P u t}+\frac{{ }_{i}^{L A W}-i^{P u t}}{\eta^{L A W}-\eta^{P u t}}\left(\eta-\eta^{P u t}\right) & \eta^{P u t} \leq \eta<\eta^{L A W} \\ { }^{L A W W} & \eta \geq \eta^{L A W}\end{cases}
$$

${ }^{9}$ He and Krishnamurthy (2019) use a similar measure of stability. They define a crisis by when a capital constraint binds for financial intermediaries and limits the equity they can raise. In our model, the equivalent notion of a binding capital constraint is precisely the sale of capital by banks because low bank equity restricts their ability to hold capital. 
This policy rule captures the idea of a Fed Put with LAW in good times. For low $\eta$, the interest rate is lowered to the constant level $i^{P u t}$, and for high $\eta$, the interest rate is raised to the constant level $i^{L A W}$. For intermediate $\eta$, the interest rate, for simplicity, increases at a linear rate from $i^{P u t}$ to $i^{L A W}$. Where the Put and LAW regions begin and end are determined by $\eta^{P u t}$ and $\eta^{L A W}$. A higher $\eta^{P u t}$ is more accommodative in two senses. First, $i^{P u t}$ holds for a larger portion of the state space. Second, the interest rate decreases at a faster rate from $i^{L A W}$. A lower $\eta^{L A W}$ has the opposite effects. Note that this class of rules includes constant nominal rates, which occur when $i^{L A W}=i^{P u t}$. With a slight abuse of notation, this class also includes piecewise rules in which the interest rate discontinuously jumps from $i^{P u t}$ to $i^{L A W}$ at $\eta^{P u t}$ if $\eta^{P u t}=\eta^{L A W}$.

Table 1: This table lists the model's parameters, our chosen values, the quantities to match, the target numbers, and the model's calculations. The target numbers are the mean values with respect to the stationary density. If a model number is reported but not the target, then we did not explicitly set a target and instead aimed for a reasonable number. Conversely, if a target number is reported but not the model number, then we are targeting the general behavior of the quantity to match. If the quantity to match is taken from the literature or chosen by another rationale, we do not report the target or the model's calculation.

Description

Bank Productivity

Household Productivity

Investment Adjustment Cost

Depreciation rate

Discount rate

Capital Growth Volatility

Tax on Banks

Liquidity Premium Coefficient

Put Interest Rate

LAW Interest Rate

Lift-Off from Put

Start LAW
Parameter Value Quantity to Match

Target Model A 
Calibration Table 1 reports our baseline calibration and the targets. Our results are qualitatively robust to alternative parameterizations. Following Brunnermeier and Sannikov (2016b), we choose the internal investment function

$$
\Phi(\imath)=\frac{1}{\varepsilon} \log (\varepsilon \imath+1)
$$

This functional form has computational advantages, but other choices like quadratic adjustment costs would yield similar results. Brunnermeier and Sannikov (2016b) sets the adjustment cost parameter $\varepsilon=10$ while the standard value of $\varepsilon$ in the literature is 3 when adjustment costs are quadratic. We choose an intermediate number and calibrate $\varepsilon=6$.

Bank productivity $a_{b}$ and capital growth volatility $\sigma$ target $2 \%$ mean consumption growth and $2 \%$ mean consumption volatility. Households are $80 \%$ as productive as banks $\left(a_{h}=0.172\right)$, which generates a mean Sharpe Ratio of $25.6 \%$ for banks. A deprecation rate of $10 \%$ is the annualized depreciation rate used in the literature. The discount rate $r=1 \%$ implies a risk-free interest rate generally between $2 \%$ and $3 \%$. The tax on banks is proportional to their equity and generates a mean leverage of 3.3. The liquidity premium coefficient is based on the microfoundation from Drechsler et al. (2018). 10

The baseline model is calibrated under the assumption that the central bank implements a Fed Put with LAW since most central banks in advanced economies arguably set rates in response to financial conditions. The Put interest rate $i^{P u t}$ is set to the zero lower bound, and the LAW interest rate $i^{L A W}$ is set to $4.5 \%$ because a steady-state nominal interest rate of $4-5 \%$ is common estimate by DSGEs. Rates are cut to the zero lower bound when the share of capital held by banks $\psi$ reaches around $50 \%$. Rates are raised to $4.5 \%$ just after $\psi$ reaches $100 \%$ to reflect the idea that monetary policy will respond only when financial distress becomes likely. For later reference, we denote this policy rule as the Baseline rule.

We interpret this rule as leaning against the wind even though the nominal rate in good times

\footnotetext{
${ }^{10}$ The funding shock size is $\kappa=40.85 \%$, and the liquidity services multiplier on reserves is $m=4$, which implies a liquidity premium coefficient of $\gamma=\kappa / m \approx 0.102$. To ensure banks always choose full insurance, we additionally set the funding shock frequency to $\chi=13 \%$, and the fire sale loss to $\rho=20 \%$, which allows a maximum interest rate of 9.2\%. If $\chi=10 \%$ and $\rho=15 \%$, as in Drechsler et al. (2018), then the maximum rate would be $5 \%$.
} 
is set to a "standard" value from the literature. Our model does not have any nominal rigidities that make positive nominal rates a natural choice. Instead, positive nominal rates insert a wedge in banks' asset pricing condition and, all else equal, disincentivize leverage. Within the lens of our model, this disincentive is precisely leaning against the wind if it is applied when $\eta$ is high.

\section{Stability and Optimal Monetary Policy}

We now consider the effect of monetary policy on financial stability and household welfare. Section 3.1 first considers the positive effects of policy rules on equilibrium, focusing on stability. Section 3.2 then considers how these positive effects translate into potential welfare gains and solves for the optimal policy within the class of rules we consider. In this section there is no macroprudential policy that could improve financial stability, and so monetary policy alone can achieve welfare-improving stability gains.

\subsection{Stability, Leverage, and Returns}

To understand how monetary policy positively affects equilibrium dynamics and stability, we first compare the policy rule under our Baseline calibration with nominal rates held constant at $i=0 \%$ and $i=4.5 \%$. Comparing the two constant rate equilibria illustrates the effects of globally higher rates; comparing with the Baseline policy illustrates the state-dependent consequences of monetary policy. Using our model as a counterfactual laboratory, we can compare these different policy rules as well as the choices of $i^{P u t}, i^{L A W}, \eta^{P u t}$, and $\eta^{L A W}$ to better understand how a Fed Put and LAW affect macroeconomic stability.

The effects of monetary policy on asset prices and volatility in our model are similar to what Drechsler et al. (2018) find in their model with two agents with heterogeneous risk aversion. In contrast, the stationary density and leverage behave differently in our model. They find that higher rates lead to lower leverage everywhere, which we do not find, and we find that changes in rates are the key determinant of leverage. This difference in leverage behavior has important consequences for the effects of a Fed Put and LAW. 
Stability Equilibrium under the Baseline policy generally resembles a combination of equilibria under the two constant rate policies 11 Despite this behavior, the Baseline rule improves stability ex-ante, in contrast to the worry that a Fed Put would be destabilizing. Stability (equation 14) under Baseline equals $85 \%$, but equals $81 \%$ and $80 \%$ under the $i=0 \%$ and $i=4.5 \%$ rules respectively. Perhaps surprisingly, the $i=4.5 \%$ rule results in the least stable economy. Figure 1 illustrates this result by plotting the stationary density of the economy under each policy, after normalizing the $\mathrm{x}$-axis and rescaling the densities to account for (small, endogenous) changes in $\eta^{*}$. In the region to the left of where a density spikes sharply (e.g. around $\eta / \eta^{*}=.45$ for the Baseline policy), banks do not hold the entire capital stock. The Baseline policy both reduces the density in this left region and shrinks the size of the crisis region since the density spikes sooner.

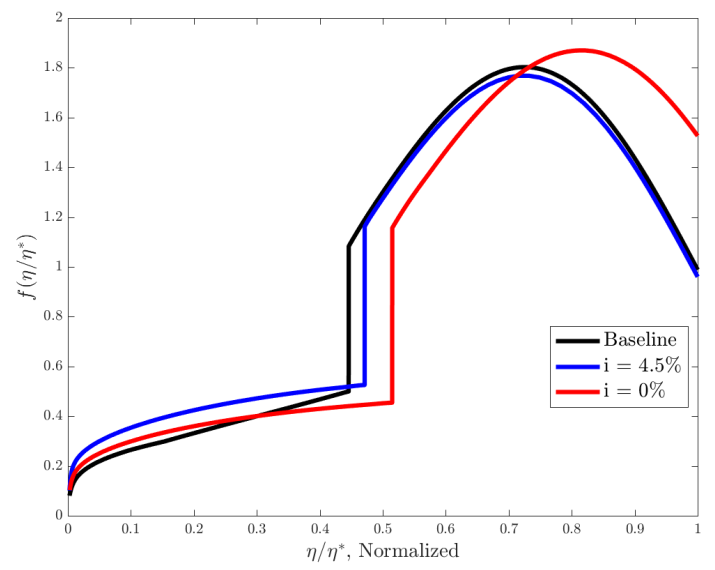

Figure 1: Stationary density (normalized support) with constant rates and Fed Put.

Leverage Figure 2(a) plots leverage levels across $\eta$ (leverage is countercyclical), and Figure 2(b) plots the percent deviation in leverage compared to the Baseline policy rule under the constant rate policies. Policy rules affect leverage differently in good and bad times. In good times, all three policy rules generate the same leverage. Explicitly, since $\psi=1$ in good times, leverage must be $1 / \eta$ in equilibrium. Changes in the nominal interest rate (and changes in banks' demand for

\footnotetext{
${ }^{11}$ We present results on stability, leverage, and returns in the main text. Appendix D.1 presents additional results on equilibrium dynamics, prices, and allocations.
} 
capital) affect the capital price in equilibrium but not bank leverage. ${ }^{12}$ In bad times, however, leverage is actually highest under the Baseline rule and substantially higher than the constant $i=$ $4.5 \%$ rule. Surprisingly, for the lowest $\eta$, leverage under the Baseline rule is also higher than the constant $i=0 \%$ rule, even though interest rates at those $\eta$ are the same in both cases; general equilibrium effects across the state space actually support higher leverage under Baseline.

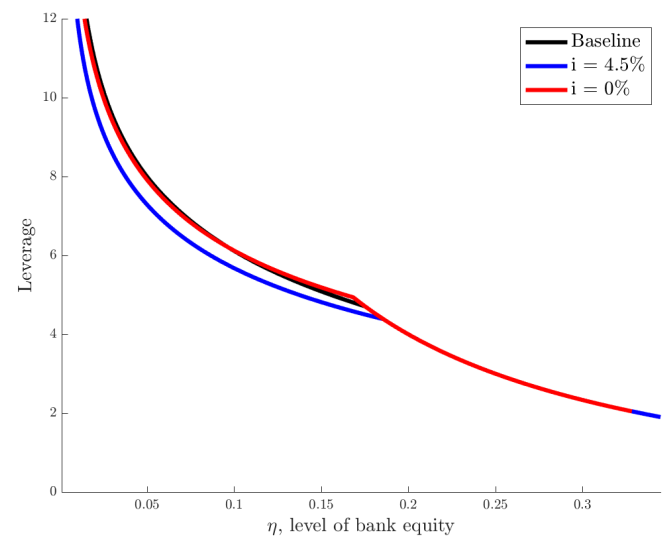

(a) Leverage

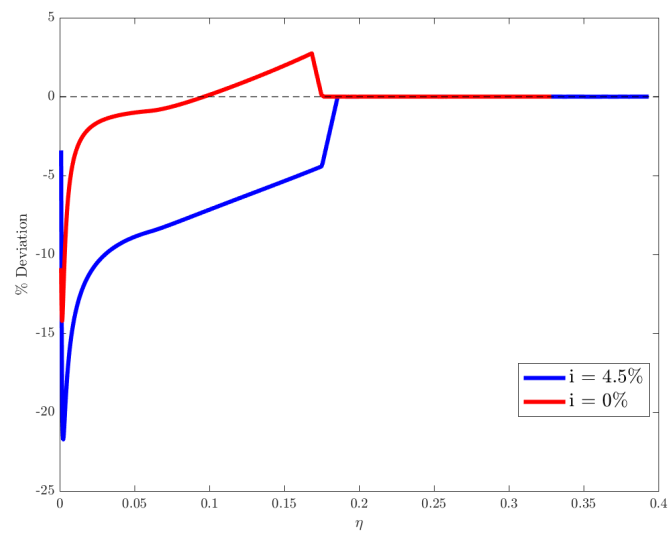

(b) Percent Deviations from Baseline

Figure 2: Equilibrium leverage with constant rates and Baseline.

Monetary policy affects leverage across the state space in this way because households are the marginal pricers of capital in bad times but banks are the marginal pricers in good times. In bad times, asset prices fall since households will only buy capital at fire-sale prices. All else equal, low rates in bad times incentivize banks to demand more capital. Banks' higher demand for capital is met by higher supply because households are less productive and are therefore willing to sell capital. In equilibrium, banks hold more capital by increasing their leverage. In contrast, during good times banks hold the entire stock of capital, so interest rates affect asset prices instead of allocations.

\footnotetext{
${ }^{12}$ In a previous version of this paper, we considered a two-good model where households specialized in the production of one good. In equilibrium they always held some capital, hence banks in good times could actually increase their leverage. However, leverage in the two-good model still behaved like leverage in this paper's one-good model. In bad times, low rates boosted leverage, but in good times the prospect of low rates in the future did not significantly boost bank leverage. The reason was the same: interest rates in good times primarily affected asset prices, not allocations. Intuitively, households were not willing to sell in good times because their capital holdings were efficiently used. While low rates in the future incentivized higher leverage by banks, no agent was willing to sell, so prices changed rather than allocations.
} 
Economists typically worry that the expectation of low rates during crises will trigger more risk taking in good times and conclude that a Fed Put will decrease stability. This is not the case in our model, which is one reason why the Baseline policy produces an ex-ante more stable economy. A Fed Put does not lead to higher leverage in good times, and high leverage during bad times boosts stability because it allows banks to earn greater excess returns and rebuild equity quickly.

Returns The other salient reason why a Fed Put with LAW improves stability is the statedependent impact on returns. Figure 3 (a) and (b) displays banks' excess returns and their Sharpe ratio, respectively. Recall from Proposition 2 that banks' hold capital if and only if

$$
\mathbb{E}\left[d r^{b}\right]=d r_{f}+\underbrace{\sigma_{c h}\left(\sigma+\sigma_{Q}\right)+E R P}_{\text {Risk Premium }}+\underbrace{L P}_{\text {Liquidity Premium }} .
$$

The RHS is banks' excess returns, and dividing the RHS by $\sigma+\sigma_{Q}$ yields the Sharpe ratio. Figure 3 (c) decomposes banks' excess returns into the risk premium and liquidity premium components, as labeled above. In bad times, returns are largely the same, but in good times, returns are much higher when interest rates are positive, with or without risk adjustments. The reason for this behavior is the state-dependent impact of the liquidity premium and thus monetary policy.

Excess returns in bad times are similar under the three policies because the liquidity premium acts a substitute for the risk premium. During bad times, the risk premium under $i=4.5 \%$ is lower than the risk premium under the other policies. The difference in risk premia arises from the difference in liquidity premia. The behavior of the risk premium under Baseline provides further evidence. When $\eta$ is very low and rates are zero under this rule, the risk premium almost coincides with the risk premium for the $i=0 \%$ policy. As $\eta$ increases and the nominal interest rate under the Baseline policy begins to increase, the risk premium deviates from the risk premium under the $i=0 \%$ policy and decreases toward the premium under the $i=4.5 \%$ policy.

Equilibrium asset pricing condition (12) illustrates why the liquidity premium substitutes for 


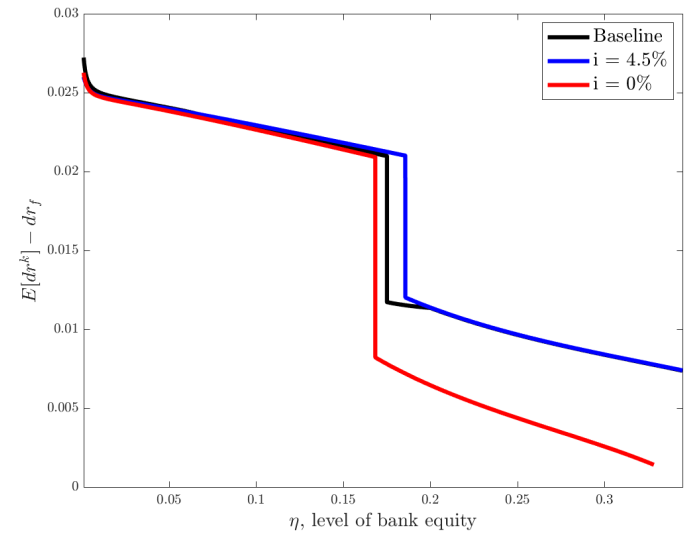

(a) Excess Returns

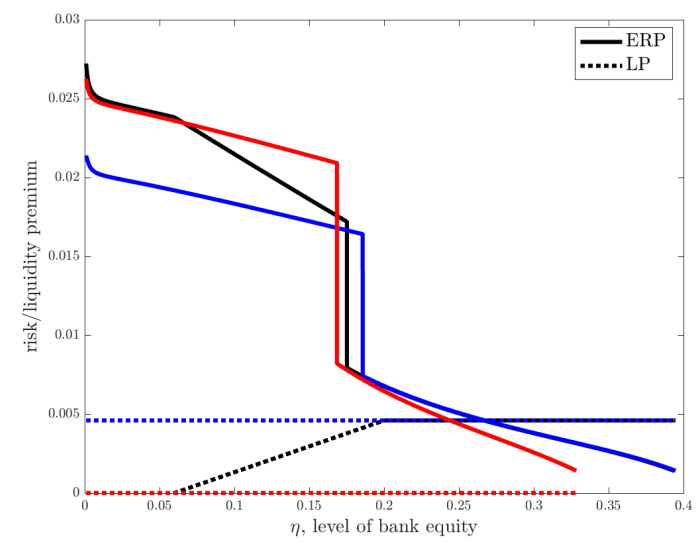

(c) Risk and Liquidity Premia

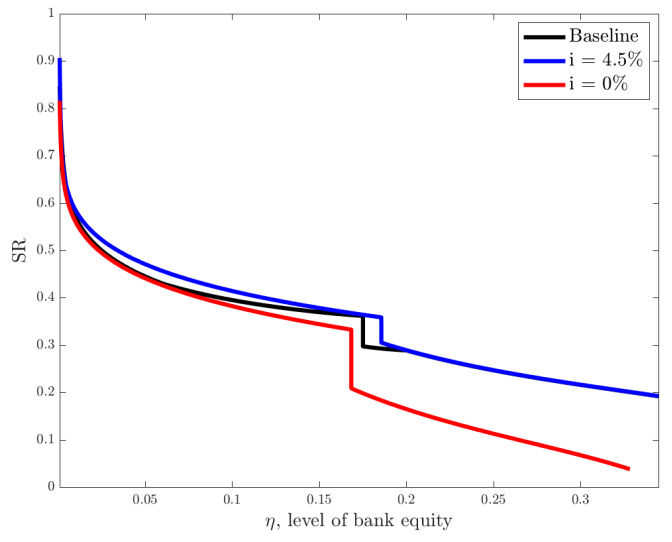

(b) Sharpe Ratio

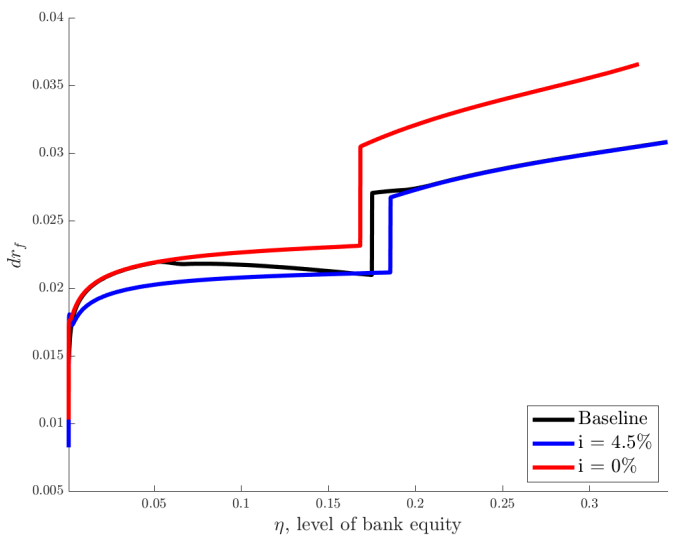

(d) Risk-Free Interest Rate

Figure 3: Equilibrium returns.

the risk premium in bad times. Recall that if households hold positive quantities of capital then

$$
\frac{a_{b}-a_{h}}{Q}=E R P+L P
$$

must hold. Quantitatively, a higher $L P$ barely changes the capital price $Q$, so the LHS of this equation is almost constant. The intuition is that households are the marginal pricers of capital during bad times. Since the liquidity premium affects banks' incentives but not households', the price of $Q$ does not strongly respond to the nominal interest rate. For the equality to hold, $E R P$ must decrease instead. A lower ERP can occur if the magnitudes of $\sigma_{\theta}, \sigma_{Q}$, and/or $\psi$ fall. In equilibrium, all three of these quantities generally decrease with the liquidity premium. 
In good times, the returns differ because the liquidity premium becomes a substitute for the risk-free interest rate (see Figure 3(d)) instead of the risk premium. While not identical, the risk premia under the three different policies are much closer to each other in good times than in bad times. In contrast, the risk-free interest rates under the three policies are similar in bad times but significantly different in good times. The reason is that the asset pricing condition (12) is slack, so expected returns now only need to satisfy (10):

$$
\underbrace{\frac{a_{b}-\imath}{Q}}_{\text {dividend yield }}+\underbrace{\Phi(\imath)-\delta+\mu_{Q}+\sigma \sigma_{Q}}_{\text {Capital Gains }}=d r_{f}+\sigma_{c h}\left(\sigma+\sigma_{Q}\right)+E R P+L P .
$$

The risk-free interest rate in good times can move to absorb most of the effects of a higher nominal rate, whereas in bad times, changes in $L P$ have to be matched by changes in $E R P$ and/or $Q$.

State-Dependency and Stability Monetary policy improves financial stability because its effects on equilibrium depend on where the economy is located in the financial cycle: the differential impact on leverage and returns is determined by whether or not banks hold the entire stock of capital. We highlight two implications.

First, if stability is the only objective, central banks should "keep their powder dry" by waiting to cut rates but then cutting quickly once a crisis occurs. We analyze the issue of timing in detail in Appendix C and summarize our results here. Stability is maximized when rates are cut just before a crisis occurs and then cut almost as much as possible. Because our model features nonlinear dynamics, changes in rates matter more than the overall level of rates. If the central bank has the flexibility to respond aggressively to financial distress, then it pays to keep the powder dry and then cut fast. These equilibrium dynamics occur when the policy is known ex-ante. If the central bank is constrained so that it cannot promise to respond aggressively to financial distress, then it is better to cut early rather than to delay.

Second, a carefully targeted policy of leaning against the wind in good times, and only in good times, promotes stability. Raising interest rates has a detrimental effect on stability if higher rates increase bank funding costs during crises, precisely when rebuilding bank equity is most valuable. 
However, when banks are well-capitalized and hold the entire capital stock, raising rates increases stability. Therefore, to stabilize the financial sector, $i^{P u t}$ should be low, and $i^{L A W}$ should be high. Appendix D.2 explores further dimensions of monetary policy’s state dependency.

\subsection{Optimal Monetary Policy}

Because households have log utility, their value function is

$$
V=\frac{\log \left(W_{h}\right)}{r}+h(\eta)
$$

where $h(\cdot)$ is a wealth-independent term. Because household wealth satisfies the identity

$$
W_{h}=N_{h}+\theta N_{b}=Q(1+(\theta-1) \eta) K
$$

the value function can be re-written into a function of $\eta$ and $K$ :

$$
V(\eta, K)=\frac{\log (K)}{r}+\frac{\log (1+(\theta-1) \eta)}{r}+\frac{\log (Q)}{r}+h(\eta)
$$

Since $\eta$ and $K$ are initial conditions, for our purposes, we may normalize $K=1$ and focus on the value function $V(\eta) \equiv V(\eta, 1)$.

Figure 4(a) plots household welfare under Baseline, $i=0 \%$, and $i=4.5 \%$ policies, and Figure 4 (b) plots consumption-equivalent welfare losses relative to Baseline. The Baseline policy yields higher household welfare than the constant rate rules for all $\eta$, and this result holds for any constant rate we considered. The stability gains from a Fed Put with LAW translate to welfare gains. The consumption-equivalent welfare losses from using one of the constant rate rules are sizable, ranging from at least $2 \%$ to low as $14 \%$ if $\eta$ is very low (see Figure 4 (b)).

Given the liquidity costs from positive nominal interest rates, in the absence of financial frictions the Friedman Rule would be optimal in our model. Proposition 4 states this explicitly for the case when banks can freely issue equity.

Proposition 4. When banks can freely issue equity (no financial frictions), the optimal nominal 


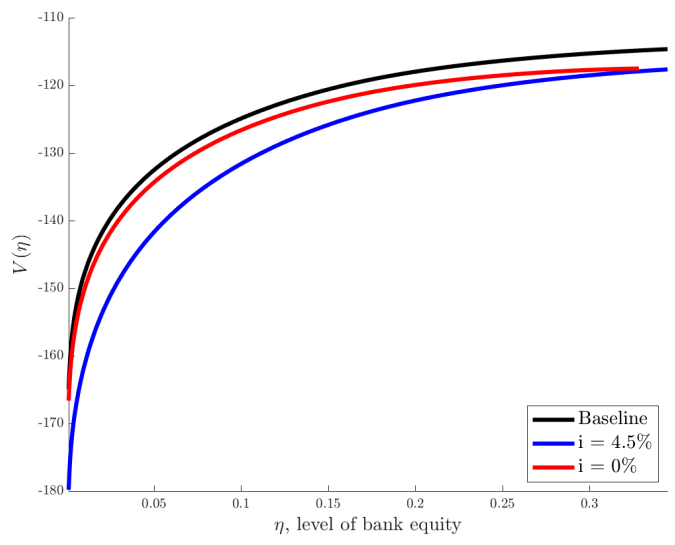

(a) Welfare

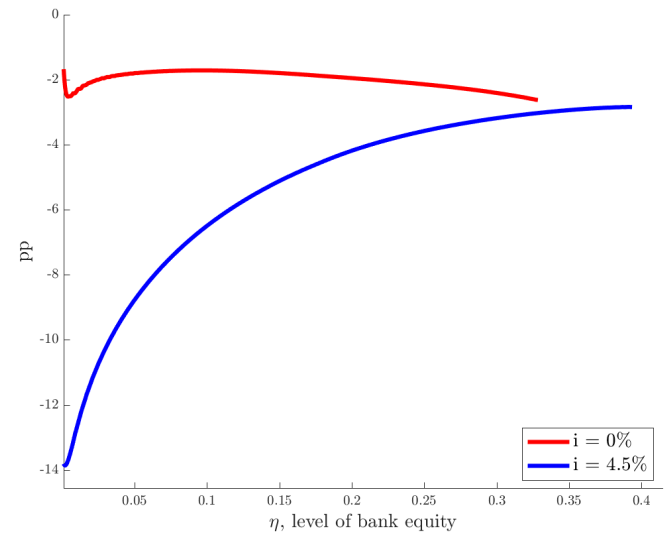

(b) Consumption equivalent relative to Baseline

Figure 4: Household welfare and consumption-equivalent welfare losses under the Baseline, $i=$ $0 \%$, and $i=4.5 \%$ policies

interest rate is $i^{*}=0$ so that the Friedman Rule holds.

The model with financial frictions features pecuniary externalities so that banks generally take excessive risk and thus the Friedman Rule need not hold. We now show that a positive liquidity premium can potentially increase welfare by decreasing banks' risk-taking to improve stability.

Optimal Policy We take a "timeless" perspective on the initial condition $\eta$ : the initial condition is not known, but we take expectations according to the stationary distribution. This "timeless" perspective calculates welfare by letting the stationary density $f(\eta)$ determine the ex-ante distribution of initial conditions and then computes $\mathbb{E}[V(\eta)]$ using the stationary distribution occurring in equilibrium. Another way to frame this exercise is that we adopt a prior on the capitalization of the financial sector and compute the expected welfare. Because our class of monetary policy rules is parameterized by the four parameters $i^{P u t}, i^{L A W}, \eta^{P u t}$, and $\eta^{L A W}$, it is numerically feasible to search for the optimal choices of these parameters. We search over a fixed parameter space to reduce computational time and because if $i^{L A W}$ is too high, then the numerical algorithm fails to find a solution to the equilibrium boundary value problem. The parameter space is $\left(i^{\text {Put }}, i^{L A W}, \eta^{P u t}, \eta^{L A W}-\eta^{P u t}\right) \in[0,0.04] \times[0,0.09] \times[0,0.18] \times[0,0.20]$, and the optimization algorithm is the interior-point method. 
The welfare results using this timeless perspective show that an aggressive Fed Put with LAW is the optimal policy. Given the functional form, the optimal policy is given by

$$
\left(\hat{i}^{P u t}, \hat{i}^{L A W}, \hat{\eta}^{P u t}, \hat{\eta}^{L A W}\right)=(0.05 \%, 8.16 \%, 14.52 \%, 19.37 \%)
$$

(Opt-NoMaP)

Since this is the welfare-maximizing (optimal) policy rule in an economy without macroprudential policy, we refer to this policy rule as the "Opt-NoMaP" rule. The optimal choice of $i^{L A W}$ is nearly twice the size of the Baseline calibration. This result provides strong evidence for the use of LAW, though we maintain a cautious interpretation of the quantitative magnitude since our model does not include standard frictions such as nominal rigidities, which would impose larger welfare losses from high interest rates.

Table 2: Welfare and stability compared to the optimal policy rule. Welfare is reported in consumption equivalent differences from the optimal policy, and stability is reported in percentage point differences from the optimal policy. "Baseline" refers to the calibrated MP rule and the other columns are constant interest rates.

\begin{tabular}{lccc}
\hline \hline & & & \\
& Baseline & $i=0 \%$ & $i=4.5 \%$ \\
& & & \\
Welfare & $-2.14 \%$ & $-5.59 \%$ & $-6.70 \%$ \\
Stability & $-4.75 \%$ & $-10.06 \%$ & $-10.74 \%$ \\
\hline \hline
\end{tabular}

Table 2 shows the welfare and stability losses from using Baseline or constant interest rate rules compared to Opt-NoMaP. Welfare losses are reported in consumption-equivalent percentages while stability losses are percentage point differences. The Baseline policy generates a sizable welfare loss at $-2.14 \%$ in consumption equivalents. The constant rate policies perform even worse, and the higher the interest rate, the worse that household welfare becomes. Larger stability losses are associated with larger welfare losses, so targeting financial stability with monetary policy improves household welfare. 
Remark on Moral Hazard Banks may take more leverage in good times because they expect rate cuts in bad times, and because of financial frictions leverage can be excessive. While aggregate leverage could be excessive, we have not modeled any reason why banks may take actions that households would not find desirable at the individual level. In reality, bank managers can be "dishonest" and misbehave. It is common to assume that bankers can "steal" capital to divert for their own consumption. Di Tella (2019) studies this form of dishonest moral hazard within a continuous-time macro-finance model and finds that bankers face a greater incentive to steal when prices are higher because they can earn more per unit of capital. In our setting, this externality would be worsened by accommodative monetary policy. Placing a similar mechanism into our model may mitigate the capacity of monetary policy to address financial stability. Banks also function as monitors for depositors (see Diamond (1984)), but screening risky investments is costly. Stable financial conditions may decrease screening effort, causing banks to systematically choose poorer quality projects. Adrian and Shin (2011) motivate a value-at-risk (VaR) constraint as the outcome of a moral hazard problem between depositors and the bank. Accommodative monetary policy may loosen banks' VaR constraints and produce even more leverage in good times, which could undo the stabilizing effects of monetary policy.

While careful considerations of additional moral hazard problems would temper our results on the margin, we conjecture that they are unlikely to reverse them. Leverage does not always systematically increase when a central bank commits to an interest rate rule that responds to financial conditions, and when leverage does increase, then it does not necessarily harm welfare. Within our model, whether monetary policy improves or worsens outcomes depends on whether households or banks are the marginal pricers of capital. If policymakers and economists believe that lower rates in bad times may lead to excessive risk taking in good times, then they should examine forms of dishonest moral hazard.

\section{Interaction of Monetary and Macroprudential Policies}

We now investigate if monetary policy still improves financial stability and/or welfare when macroprudential policy (MaP) is also applied. We have so far found evidence that a Fed Put with LAW 
promotes both financial stability and welfare. These results extend so long as macroprudential policy is insufficient to address financial stability on its own. Monetary policy has scope to improve stability and welfare if macroprudential policy does not restrict leverage at the right time. The key reason is that banks choose socially suboptimal levels of leverage only for certain ranges of $\eta$, so macroprudential policy has to limit leverage at the correct locations in the state space.

\subsection{Macroprudential Policy Rules}

We model macroprudential policy as a leverage constraint that depends on $\eta$. For some function $L(\eta)$, the share of capital allocated to banks must satisfy

$$
\frac{\psi}{\eta}-1 \leq L(\eta)
$$

Since all variables in the model depend on $\eta$ in equilibrium, this constraint can also be written as a function of other quantities like the marginal value of bank equity rather than $\eta$ directly. The presence of leverage constraints changes some of the equilibrium conditions used to derive Lemma 1 (see Appendix A).

\subsection{Well-Targeted Macroprudential Policy}

It is useful to divide the state space into three regions: "Crisis" when $\eta$ is very low; "Distress" when $\eta$ is intermediate and banks still hold a large fraction of capital; and "Boom" times when $\eta$ is sufficiently high that banks hold all capital $(\psi=1)$. The phase(s) in which leverage constraints bind determine the consequences for equilibrium dynamics and welfare. Because bank leverage is countercyclical in equilibrium, leverage constraints that are simply defined are likely to bind when the economy is already in a downturn. However, this is precisely when output is the worst and the need to rebuild equity is the greatest.

We find that macroprudential policy performs best if it primarily restricts leverage during the "Boom" phase of the financial cycle and allows more leverage during the downturn. One such 
natural rule ties leverage to the marginal value of bank equity:

$$
L(\eta)=\alpha \theta
$$

This constraint is close to the incentive-compatibility constraint on leverage used in Van der Ghote (2020), and so we call (17) the "ICC" macroprudential policy. The coefficient $\alpha$ parameterizes how stringent the leverage constraint is. This rule encourages countercyclical leverage ( $\theta$ decreases with $\eta$ ). When $\theta$ is low (during the Boom) bank leverage cannot be too high, but if bank equity is low, then the constraint relaxes, allowing banks to borrow more.

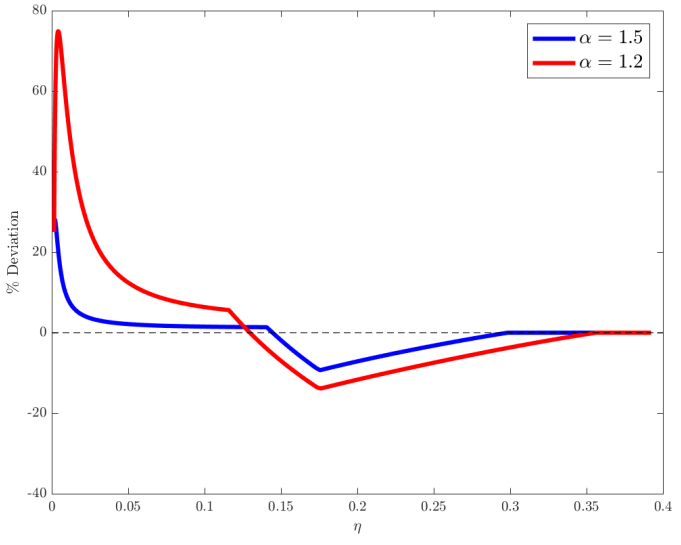

(a) Leverage, percent deviations

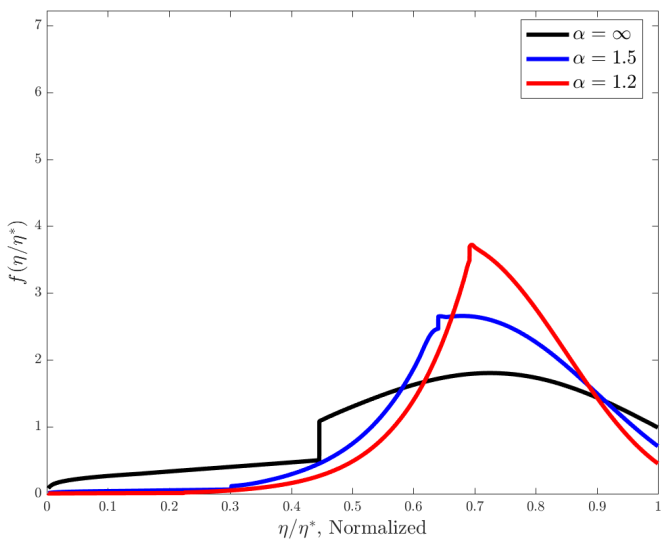

(b) Stationary density

Figure 5: Leverage and stability when the ICC macroprudential policy is applied in addition to Baseline.

Figure 5 plots leverage and the stationary density when the ICC policy is applied and monetary policy follows the Baseline rule. Figure 5(a) plots the percent deviations in leverage compared to equilibrium with no ICC policy (i.e., $\alpha=\infty$ ). The ICC policy leads to lower leverage in Distress and Boom times $\sqrt{13}$ Crucially, compared to the equilibrium without any leverage constraints, the general equilibrium consequences of lower leverage in Distress times is that leverage with the ICC policy is higher in Crisis times. Because the ICC policy boosts leverage in bad times but dampens

\footnotetext{
${ }^{13}$ More precisely, the ICC policy causes lower leverage in the regions of the state space that would be classified as Distress and Boom times if the Baseline rule without an ICC policy was used. Of course, by definition, leverage is the same for $\eta$ belonging to the Boom phase with or without ICC policy. Nonetheless, the ICC policy affects other variables, such as drift and volatility, over these $\eta$.
} 
leverage in good times, the economy is overall more stable, as illustrated in Figure 5(b). The drift of bank equity increases everywhere and systemic risk generally falls when the ICC policy is applied. Although the ICC policy lengthens the region where $\psi<1$, the higher drift and lower volatility prevent the economy from slipping into deep recessions ( $\eta$ stays far away from zero).

Table 3: Welfare gains relative to Baseline, with ICC policy. Welfare is reported in consumption equivalent differences from the Baseline calibration. The "Opt-NoMap" policy is the optimal MP rule without macroprudential policy (see Section 3); the other columns consider constant rates.

\begin{tabular}{lccc}
\hline \hline & & & \\
MaP Constraint & Opt-NoMap & $i=0 \%$ & $i=4.5 \%$ \\
\hline & & & \\
None $(\alpha=\infty)$ & $2.51 \%$ & $-3.15 \%$ & $-4.36 \%$ \\
$\alpha=1.6$ & $-4.67 \%$ & $1.97 \%$ & $-0.84 \%$ \\
$\alpha=1.15$ & $-2.54 \%$ & $1.58 \%$ & $0.03 \%$ \\
& & & \\
\hline \hline
\end{tabular}

The presence of the ICC policy completely changes the welfare consequences of monetary policy rules. Welfare is now maximized when monetary policy ignores financial stability, adopting the Friedman rule to minimize liquidity costs from positive nominal interest rates. Table 3 displays welfare gains relative to the Baseline rule, varying the tightness of the ICC policy and the type of monetary policy. Figure 6 plots welfare and stability, varying the tightness of the ICC policy $\alpha$, for the Opt-NoMaP rule and a constant $i=0 \%$ rule. The Friedman rule $(i=0 \%)$ is now associated with a welfare gain of roughly $2 \%$ in consumption equivalents relative to the Baseline rule, whereas without the ICC policy the $i=0 \%$ policy results in a welfare loss of $-3.15 \%$ relative to Baseline ${ }^{14}$

Additionally, with the ICC policy a higher $i^{L A W}$ no longer improves welfare (a higher $i^{P u t}$ still hurts welfare). A Fed Put with LAW is not necessary when the ICC policy regulates leverage. Figure 7 plots welfare while varying two sets of MP rules in the presence of the ICC constraint. Figure 7 (a) considers a Fed Put with $\eta^{L A W}, \eta^{P u t}, i^{L A W}$ set to the Baseline calibration and varies

\footnotetext{
${ }^{14}$ Welfare with the ICC policy is not monotonic in $\alpha$, regardless of the monetary policy rule, which is shown in Figure 6(a) for the Opt-NoMap policy and $i=0 \%$, reflecting the tradeoff between stability and output: tighter MaP constraints improve stability, but at the cost of lower flow output and growth. Thus, welfare is generally maximized for an interior value of the ICC policy.
} 


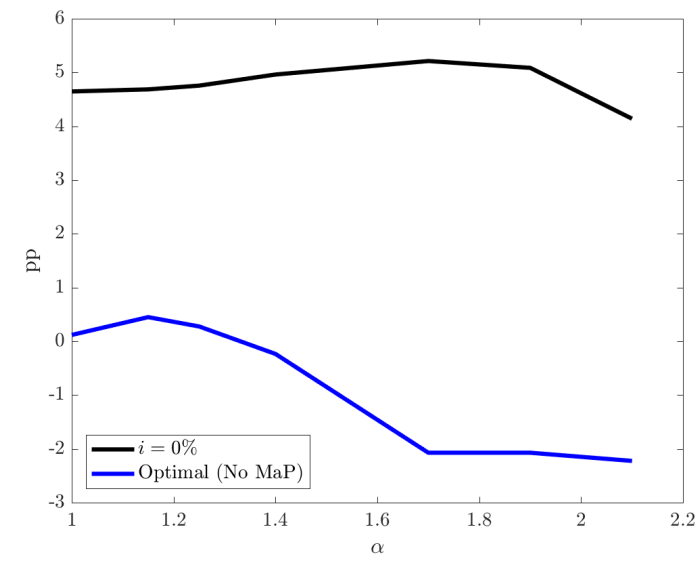

(a) Ex-Ante Welfare Gains

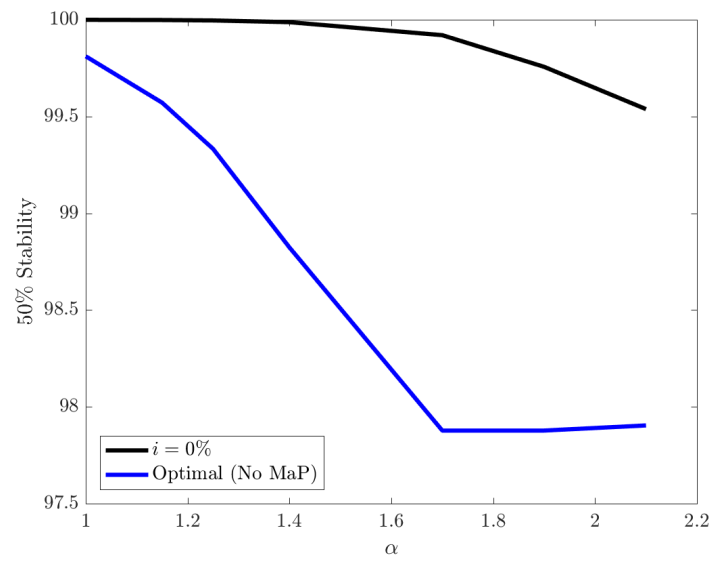

(b) $\psi \geq 50 \%$ Stability

Figure 6: Welfare and stability varying $\alpha$ under the Opt-NoMaP monetary policy rule and the $i=0 \%$ rule. Welfare gains are calculated in consumption equivalents relative to Baseline.

$i^{L A W}$, given an ICC constraint with $\alpha=1.2,1.7,2.2$. In each case, welfare is decreasing in $i^{L A W}$ so that it is no longer optimal for monetary policy to pursue a Fed Put with LAW. 7(b) considers constant interest rate rules and confirms that low interest rates are also optimal in the presence of the ICC constraint. Proposition 4 shows that the Friedman rule is optimal in the absence of financial frictions; these results suggest that the Friedman rule also maximizes welfare when MaP can adequately address externalities caused by financial frictions.

The ICC policy erases the need for active monetary policy because it restricts leverage during the appropriate phases of the financial cycle-during the Boom and Distress periods 15 Asset price volatility is the highest when banks start to sell capital to households (Distress), hence the economy's pecuniary externality is the largest at that time (see Van der Ghote, 2020). Binding leverage constraints during the Distress and Boom phases mitigate this externality. Accordingly, the ICC policy dampens asset price volatility during the Distress phase and thereby reduces the severity of the initial fire sales.

Restricting leverage during the Boom phase forces banks to sell capital to households and causes a shallow recession. By accepting some output losses earlier in the financial cycle, macro-

\footnotetext{
${ }^{15}$ As before, leverage is restricted in the sense that the ICC policy decreases leverage in the regions of the state space that would be classified as Distress and Boom times if the Baseline rule without an ICC policy was used.
} 


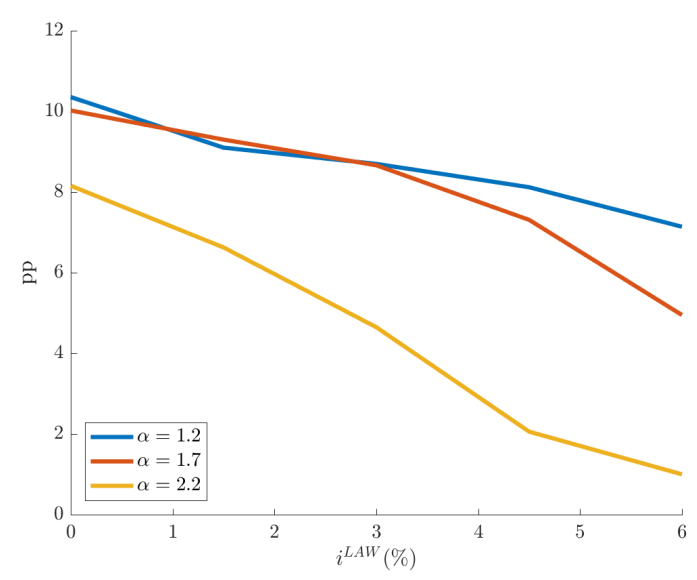

(a) Varying $i^{L A W}$

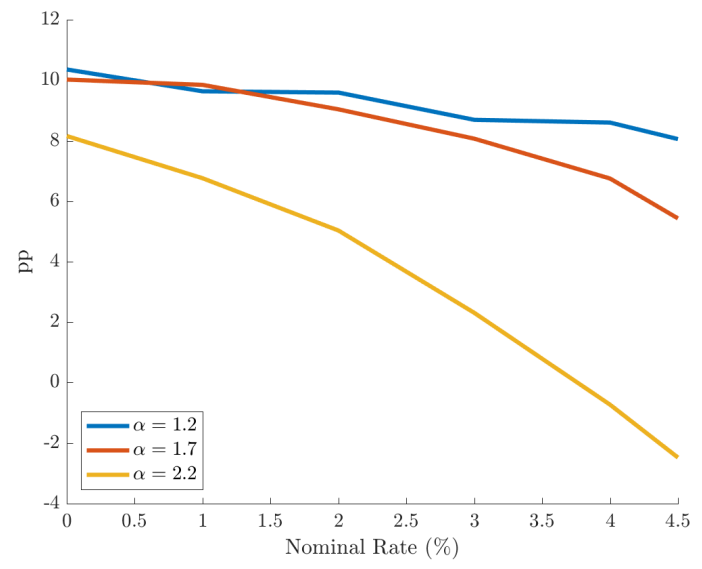

(b) Constant interest rates

Figure 7: Welfare and MP rules in the presence of ICC constraints. Figure (a) sets $\eta^{L A W}, \eta^{P u t}, i^{L A W}$ to the Baseline calibration and varies $i^{L A W}$ (on the X-axis). Figure (b) considers constant interest rate rules and varies the interest rate. Each line corresponds to tightness of the ICC constraint. Welfare differences are reported in consumption equivalents relative to Baseline.

prudential policy lowers the probability of a severe recession and further reduces the severity of fire sales. We further corroborate this conclusion by substituting the ICC policy with piecewise linear leverage constraints during both the Distress and Boom phases. This simpler rule restricts leverage in approximately the same regions of the state space as the ICC policy and also causes the $i=0 \%$ rule to outperform the Baseline rule, which shows that the key characteristic of the ICC policy is its impact on leverage during the Distress and Boom phases.

The mechanics of how MaP and MP affect welfare and stability are somewhat different. Monetary policy increases welfare primarily by increasing leverage in bad times so that flow outcomes improve and banks rebuild equity more quickly. In contrast, the ICC policy improves outcomes on average by forcing banks to sell capital sooner, creating a small recession so that the likelihood of a severe recession falls: when leverage limits bind, intermediation falls and flow outcomes suffer, but binding leverage limits increase banks' investment returns and so banks may rebuild equity faster. If we modify our definition of stability in equation (14) to measure the probability that $\psi$ is greater than or equal to $50 \%, 25 \%$, or $10 \%$, then the ICC policy with $i=0 \%$ does improve stability (properly defined) relative to the ICC policy with the Baseline monetary policy in all three cases. Figure 6.b) verifies that stability, when measured as the probability that $\psi \geq 50 \%$, decreases 
with $\alpha$. When MaP is well-targeted, the general equilibrium consequences support higher leverage in Crisis times, mirroring the effects of decreasing interest rates following a Fed Put. These differences between how MaP and MP affect welfare and stability are precisely why well-targeted leverage constraints obviate the need for monetary policy to target financial conditions.

\subsection{Poorly-Targeted Macroprudential Policy}

With well-targeted macroprudential policy, monetary policy should not target financial stability. However, our results from Section 3 (monetary policy can improve stability and welfare) continue to hold so long as leverage constraints are poorly targeted. Appendix D.3 formalizes these results, considering simple piecewise-linear leverage constraints that bind only during the Crisis or Distress regions, which is where simply-defined policies are likely to bind. Leverage constraints during the Crisis and Distress phases of the financial cycle turn out to be poorly targeted, failing to restrict leverage when leverage exceeds the social optimum. For both types of macroprudential policies, a Fed Put with LAW still improves household welfare and outperforms constant rate rules. With poorly targeted leverage constraints, the Baseline rule always outperforms constant rate rules, and rules with more aggressive Put or LAW improve welfare and stability. The Distress policy does improve household welfare relative to the case of no leverage constraints, so it mitigates excessive risk taking but could be better targeted by additionally restricting leverage during the Boom.

Our results regarding the interaction of macroprudential and monetary policies can be interpreted in light of the so-called Tinbergen (1952) principle, that a policymaker with $n$ independent objectives needs $n$ policy tools. Our model is dynamic with state-contingent effects from policy (and externalities). To address financial and price stability together, policy makers do not only need 2 policy tools - they must also have sufficiently flexible tools. Addressing financial stability therefore requires appropriately designed macroprudential limits. In reality, macroprudential tools may be restricted as a result of regulation or challenges to implementation, whereas monetary policy rules can be extremely nimble, responding immediately to financial stability concerns if the central bank so chooses. If macroprudential tools are inflexible and cannot target sources of financial instability at the correct time, then scope remains for monetary policy to address financial 
stability (see also Caballero and Simsek, 2019). Conversely, monetary policy is free to focus on conventional targets (e.g. a stable price level) as its sole objectives only if macroprudential tools are sufficient to mitigate financial crises.

Leverage constraints are not the only instrument in the macroprudential policy toolkit. Appendix A.2.6 models "boundary condition" macroprudential tools such as equity injections. The numerical implementation of these policies amounts to changing the boundary conditions for the equilibrium system of differential equations. We find that equity injections can also substitute for active monetary policy. If these injections are sufficiently aggressive so that banks are able to always hold the entire capital stock, then monetary policy becomes unnecessary for stabilization. However, achieving this objective may require quite active equity injections. In contrast, taxing or subsidizing dividends does little quantitatively to improve outcomes.

\section{Conclusion}

We provide a macroeconomic model with a financial sector in which monetary policy endogenously determines the stability of the economy and therefore determines the probability and severity of crises. Monetary policy influences outcomes by affecting risk and liquidity premia. Policies that combine leaning against the wind in good times with accommodative rates during financial distress can substantially improve stability and household welfare. The consequences of monetary policy for financial stability are state-dependent, so the stability benefits of monetary policy depend critically on the timing. Cutting rates during financial crises (and only then) yield the greatest stability gains. When macroprudential policies are poorly targeted, monetary policy should target financial stability, but when macroprudential policies are sufficiently well-targeted, then monetary policy should not target financial stability.

\section{References}

ACharya, V., I. Gujral, N. KulKarni, And H. Shin (2011): "Dividends and bank capital in the financial crisis of 2007-2009," Tech. rep., National Bureau of Economic Research. 
ADRIAN, T. AND F. DUARTE (2016): "Financial vulnerability and monetary policy," Tech. rep., FRB of NY Staff Report.

Adrian, T., F. Duarte, F. Grinberg, and T. Mancini Griffoli (2019): "Monetary policy and financial conditions: a cross-country study," FRB of New York Staff Report.

AdriAn, T. AND N. LIANG (2016): "Monetary policy, financial conditions, and financial stability,” Tech. rep., CEPR Discussion Paper No. DP11394.

ADRIAN, T. AND H. SHIN (2010): “Liquidity and Leverage," Journal of Financial Intermediation, $19,418-437$.

(2011): "Procyclical Leverage and Value at Risk," Federal Reserve Bank of New York Staff Reports, N 338.

Bernanke, B. And M. Gertler (1989): “Agency Costs, Net Worth, and Business Fluctuations," The American Economic Review, 79, pp. 14-31.

Bernanke, B. S., M. Gertler, And S. Gilchrist (1999): "The financial accelerator in a quantitative business cycle framework," in Handbook of Macroeconomics, ed. by J. B. Taylor and M. Woodford, Elsevier, vol. 1 of Handbook of Macroeconomics, chap. 21, pp. 1341-1393.

Bernanke, B. S. AND K. N. KutTneR (2005): "What explains the stock market's reaction to Federal Reserve policy?” The Journal of finance, 60, 1221-1257.

Bigio, S. And Y. SAnnikov (2019): “A Model of Credit, Money, Interest, and Prices,” Working paper.

BIS (2014): “84th Annual Report,” Bank for International Settlements.

(2016): “86th Annual Report,” Bank for International Settlements.

BORIO, C. (2014): "Monetary policy and financial stability: what role in prevention and recovery?" Bank for International Settlements Working Papers.

Borio, C. E., P. Disyatat, M. Juselius, and P. Rungcharoenkitkul (2018): "Monetary policy in the grip of a pincer movement," Bank for International Settlements Working Papers.

Bornstein, G. And G. Lorenzoni (2018): "Moral Hazard Misconceptions: The Case of the Greenspan Put," IMF Economic Review, 66, 251-286.

BRUnNeRmeIER, M. K. AND Y. Koby (2018): “The reversal interest rate,” Tech. rep., National Bureau of Economic Research. 
Brunnermeier, M. K. AND Y. S Annikov (2014): "A Macroeconomic Model with a Financial Sector," American Economic Review, 104, 379-421.

- (2015): "International Credit Flows and Pecuniary Externalities," American Economic Journal: Macroeconomics, 7, 297-338.

_ (2016a): “The I theory of money," Tech. rep., National Bureau of Economic Research.

- (2016b): "Macro, money, and finance: A continuous-time approach," in Handbook of Macroeconomics, Elsevier, vol. 2, 1497-1545.

Caballero, R. J. And A. Simsek (2019): “Prudential Monetary Policy,” Tech. rep., National Bureau of Economic Research.

- (2020): “A Risk-Centric Model of Demand Recessions and Speculation," The Quarterly Journal of Economics, 135, 1493-1566.

CAmpbell, J. R., F. Ferroni, J. D. Fisher, And L. Melosi (2019): “The limits of forward guidance," Journal of Monetary Economics.

Christiano, L. J., M. S. Eichenbaum, And M. Trabandt (2015): "Understanding the great recession," American Economic Journal: Macroeconomics, 7, 110-67.

Cieslak, A. And A. Vissing-Jorgensen (2020): “The Economics of the Fed put," Working Paper 26894.

CÚRdiA, V. AND M. WoOdFord (2011): “The central-bank balance sheet as an instrument of monetarypolicy," Journal of Monetary Economics, 58, 54-79.

(2016): “Credit frictions and optimal monetary policy," Journal of Monetary Economics, $84,30-65$.

Di Tella, S. (2019): "Optimal Regulation of Financial Intermediaries," American Economic Review, 109, 271-313.

DiAmond, D. W. (1984): “Financial Intermediation and Delegated Monitoring," The Review of Economic Studies, 51, 393-414.

DiAmOND, D. W. AND R. G. RAJAN (2012): "Illiquid banks, financial stability, and interest rate policy," Journal of Political Economy, 120, 552-591.

Drechsler, I., A. Savov, And P. Schnabl (2017): “The deposits channel of monetary policy," The Quarterly Journal of Economics, 132, 1819-1876. 


\section{3.}

FARHi, E. AND J. TiRole (2012): “Collective Moral Hazard, Maturity Mismatch, and Systemic Bailouts," American Economic Review, 102, 60-93.

GAMBACORTA, L. AND H. S. SHIN (2016): "Why bank capital matters for monetary policy," Journal of Financial Intermediation.

GERTLER, M. AND P. KARADI (2011): “A model of unconventional monetary policy,” Journal of monetary Economics, 58, 17-34.

HANSEN, J. (2018): “Optimal monetary policy with capital and a financial accelerator,” Journal of Economic Dynamics and Control, 92, 84-102.

He, Z. And A. Krishnamurthy (2012): “A Model of Capital and Crises," The Review of Economic Studies, 79, 735-777.

- (2013): “Intermediary Asset Pricing," American Economic Review, 103, 732-70.

- (2019): "A macroeconomic framework for quantifying systemic risk," American Economic Journal: Macroeconomics, 11, 1-37.

Juselius, M., C. E. Borio, P. Disyatat, And M. Drehmann (2017): "Monetary policy, the financial cycle and ultralow interest rates," International Journal of Central Banking, 13.

KeKre, R. And M. Lenel (2019): “Monetary Policy, Redistribution, and Risk Premia,” Princeton.

Kiyotaki, N. And J. Moore (1997): “Credit Cycles,” Journal of Political Economy, 105, pp. $211-48$.

LENEL, M., M. PiAZZESI, AND M. SCHNEIDER (2019): "The short rate disconnect in a monetary economy," Journal of Monetary Economics, 106, 59-77.

Phelan, G. (2016): "Financial intermediation, leverage, and macroeconomic instability," American Economic Journal: Macroeconomics, 8, 199-224.

REIFSCHNEIDER, D. AND J. C. WiLliAMS (2000): “Three lessons for monetary policy in a lowinflation era," Journal of Money, Credit and Banking, 936-966.

STEIN, J. C. (2012): "Monetary policy as financial stability regulation,” The Quarterly Journal of Economics, 127, 57-95. 
SVEnsson, L. E. (2017): "Cost-benefit analysis of leaning against the wind," Journal of Monetary Economics, 90, 193-213.

Tinbergen, J. (1952): On the Theory of Economic Policy, N.

VAn Der Ghote, A. (2019): "Liquidity Management, Leverage, and Monetary Policy," Tech. rep., European Central Bank.

(2020): "Coordinating Monetary and Financial Regulatory Policies," American Economic Journal: Macroeconomics, forthcoming.

\section{Appendices for Online Publication}

\section{A Proofs and Additional Equations}

\section{A.1 Proofs}

Proof of Proposition 1] Conjecture that households have a twice-differentiable value function

$$
V_{t}=\frac{\log \left(w_{h, t}\right)}{r}+h_{t}=\frac{\log \left(n_{h, t}+\theta_{t} n_{b, t}\right)}{r}+h_{t},
$$

where $h_{t}$ is independent of household wealth. By Ito's lemma, households' HJB is

$$
\begin{aligned}
\log \left(w_{h, t}\right)+r h_{t} & =\max _{x_{h, t} \geq 0, c_{h, t}, l_{t}} \log \left(c_{h, t}\right)+\frac{1}{r\left(n_{h, t}+\theta_{t} n_{b, t}\right)} \mu_{w h, t} w_{h, t}-\frac{1}{2 r\left(n_{h, t}+\theta_{t} n_{b, t}\right)^{2}}\left(\sigma_{w h, t} w_{h, t}\right)^{2} \\
& =\max _{x_{h, t} \geq 0, c_{h, t}, l_{t}} \log \left(c_{h, t}\right)+\frac{1}{r} \mu_{w h, t}-\frac{1}{2 r} \sigma_{w h, t}^{2} .
\end{aligned}
$$

Let $\omega_{t} \equiv n_{h, t} / w_{h, t}$. Then $w_{h, t}$ follows the process

$$
\begin{aligned}
\frac{d w_{h, t}}{w_{h, t}}= & \left\{\omega_{t} \mu_{n h, t}+\left(1-\omega_{t}\right)\left(\mu_{\theta, t}+\mu_{n b, t}+\sigma_{\theta, t} \sigma_{n b, t}\right)\right\} d t \\
& +\left\{\omega_{t} \sigma_{n h, t}+\left(1-\omega_{t}\right)\left(\sigma_{\theta, t}+\sigma_{n b, t}\right)\right\} d W_{t} .
\end{aligned}
$$


Further, because $\sigma_{n h, t}=x_{h, t}\left(\sigma+\sigma_{Q, t}\right)$,

$$
\frac{\partial \sigma_{w h, t}}{\partial x_{h, t}}=\omega_{t} \frac{\partial \sigma_{n, t}}{\partial x_{h, t}}=\omega_{t}\left(\sigma+\sigma_{Q, t}\right) .
$$

Given this observation and (18), the first-order conditions are

$$
\begin{aligned}
\left(x_{h, t}\right): \quad 0 & =\frac{\omega_{t}}{r}\left(\mathbb{E}\left[d r_{t}^{h}\right]-d r_{f, t}\right)-\frac{1}{r} \sigma_{w h, t} \frac{\partial \sigma_{w h, t}}{\partial x_{h, t}} \\
& =\omega_{t}\left(\mathbb{E}\left[d r_{t}^{h}\right]-d r_{f, t}-\sigma_{w h, t}\left(\sigma+\sigma_{Q, t}\right)\right) \\
\Rightarrow \mathbb{E}\left[d r_{t}^{h}\right]-d r_{f, t} & =\sigma_{w h, t}\left(\sigma+\sigma_{Q, t}\right) \\
\left(c_{h, t}\right): \quad 0 & =\frac{1}{c_{h, t}}-\frac{1}{r} \omega_{t} \frac{1}{n_{h, t}} \\
& =\frac{1}{c_{h, t}}-\frac{1}{r n_{h, t}} \\
\Rightarrow c_{h, t} & =r w_{h, t} \\
\left(l_{t}\right): \quad \Phi^{\prime}\left(l_{t}\right) & =\frac{1}{Q_{t}}
\end{aligned}
$$

Since consumption is proportional to wealth,

$$
\sigma_{c h, t}=\omega_{t} \sigma_{n h, t}+\left(1-\omega_{t}\right)\left(\sigma_{\theta, t}+\sigma_{n b, t}\right),
$$

hence the first-order condition for $x_{h, t}$ equates expected excess returns with the covariance of household consumption and returns.

Proof of Proposition 2. Homogeneity and price-taking imply that banks' value function takes the form $U_{t}=\theta_{t} n_{b, t}$, where $\theta_{t}$ is the marginal value of banks' equity. Further, households' discount factor is $\xi_{t}=e^{-r t} c_{h, t}^{-1}$ because households have log utility.

Therefore, the HJB can be written as

$$
r \theta_{t} n_{b, t} c_{h, t}^{-1}=\max _{x_{b, t} \geq 0, d \zeta_{t}, l_{t}} d \zeta_{t} c_{h, t}^{-1}+\mathbb{E}\left[d\left(\theta_{t} n_{b, t} c_{h, t}^{-1}\right)\right]
$$

subject to the constraints (5) and (6). 
Conjecture that $\theta_{t}$ and $c_{h, t}$ both follow diffusions. By Ito's product rule,

$$
\frac{d\left(\theta_{t} n_{b, t}\right)}{\theta_{t} n_{b, t}}=\left(\mu_{\theta, t}+\mu_{n b, t}+\sigma_{\theta, t} \sigma_{n b, t}\right) d t+\left(\sigma_{\theta, t}+\sigma_{n b, t}\right) d W_{t}
$$

By Ito's product and quotient rules,

$$
\begin{aligned}
& \left(\theta_{t} n_{b, t} c_{h, t}^{-1}\right) \mathbb{E}\left[\frac{d\left(\theta_{t} n_{b, t} c_{h, t}^{-1}\right)}{\theta_{t} n_{b, t} c_{h, t}^{-1}}\right] \\
& =\mu_{\theta, t}+\mu_{n b, t}+\sigma_{\theta, t} \sigma_{n b, t}+\sigma_{c h, t}^{2}-\mu_{c h, t}-\sigma_{c h, t}\left(\sigma_{\theta, t}+\sigma_{n b, t}\right) .
\end{aligned}
$$

After dropping the differential $d t$, equation (20) becomes

$$
r \theta_{t} n_{b, t} c_{t}^{-1}=\max _{x_{b, t} \geq 0, l_{t}, d \zeta_{b, t} \geq 0} c_{t}^{-1} d \zeta_{b, t}+\theta_{t} n_{b, t} c_{t}^{-1}\left(\mu_{\theta, t}+\mu_{n b, t}-\mu_{c h, t}+\sigma_{c h, t}^{2}+\sigma_{\theta, t} \sigma_{n b, t}-\sigma_{c h, t} \sigma_{n b, t}-\sigma_{c h, t} \sigma_{\theta, t}\right)
$$

Dividing through by $\theta_{t} n_{b, t} c_{t}^{-1}$ and substituting wealth terms obtains

$$
\begin{aligned}
r= & \max \frac{d \zeta_{b, t}}{\theta_{t} n_{b, t}}+\mu_{\theta, t}+d r_{f, t}+x_{b, t}\left(\mathbb{E}\left[d r_{b, t}\right]-d r_{f, t}\right)-\gamma x_{b, t} i_{t}+\gamma i_{t}-T_{t}-\frac{d \zeta_{b, t}}{n_{b, t}} \\
& -\mu_{c h, t}+\sigma_{c h, t}^{2}+x_{b, t} \sigma_{\theta, t}\left(\sigma+\sigma_{Q, t}\right)-x_{b, t} \sigma_{c h, t}\left(\sigma+\sigma_{Q, t}\right)-\sigma_{c h, t} \sigma_{\theta, t}
\end{aligned}
$$

By the stochastic maximum principle, the risk-free interest rate satisfies

$$
d r_{f, t}=r+\mu_{c h, t}-\sigma_{c h, t}^{2}
$$

Substitution and re-arranging yields

$$
\begin{aligned}
d r_{f, t}= & \max \frac{d \zeta_{b, t}}{n_{b, t}}\left(\frac{1}{\theta_{t}}-1\right)-T_{t}+\mu_{\theta, t}-\sigma_{c h, t} \sigma_{\theta, t}+d r_{f, t} \\
& x_{b, t}\left(\mathbb{E}\left[d r_{b, t}\right]-d r_{f, t}+\left(\sigma_{\theta, t}-\sigma_{c h, t}\right)\left(\sigma+\sigma_{Q, t}\right)\right)-\gamma x_{b, t} i_{t}+\gamma i_{t} \\
T_{t}= & \max \frac{d \zeta_{b, t}}{n_{b, t}}\left(\frac{1}{\theta_{t}}-1\right)+\mu_{\theta, t}-\sigma_{c h, t} \sigma_{\theta, t} \\
& x_{b, t}\left(\mathbb{E}\left[d r_{b, t}\right]-d r_{f, t}+\left(\sigma_{\theta, t}-\sigma_{c h, t}\right)\left(\sigma+\sigma_{Q, t}\right)\right)-\gamma x_{b, t} i_{t}+\gamma i_{t}
\end{aligned}
$$


The first-order conditions imply

$$
\begin{gathered}
d \zeta_{b, t}>0 \text { if } \theta_{t} \leq 1 \\
d \zeta_{b, t}=0 \text { if } \theta_{t}>1 \\
\mathbb{E}\left[d r_{b, t}\right]-d r_{f, t}=\left(\sigma_{c h, t}-\sigma_{\theta, t}\right)\left(\sigma+\sigma_{Q, t}\right)+\gamma i_{t} \\
\Phi^{\prime}\left(l_{t}\right)=\frac{1}{Q_{t}} .
\end{gathered}
$$

Plugging these first-order conditions into the HJB and re-arranging yields

$$
\mu_{\theta, t}=T_{t}+\sigma_{c h, t} \sigma_{\theta, t}-\gamma i_{t}
$$

Proof of Lemma 11. After substituting banks' asset pricing condition and using $x_{b, t}=\psi_{t} / \eta_{t}$, the process for banks' aggregate equity $N_{b, t}$ is

$$
\begin{aligned}
\frac{d N_{b, t}}{N_{b, t}}= & \left(d r_{f, t}-\gamma\left(\frac{\psi_{t}}{\eta_{t}}-1\right) i_{t}-T_{t}+\frac{\psi_{t}}{\eta_{t}}\left(\sigma_{c h, t}-\sigma_{\theta, t}\right)\left(\sigma+\sigma_{Q, t}\right)+\frac{\psi_{t}}{\eta_{t}} \gamma i_{t}-\frac{d \zeta_{b, t}}{N_{b, t}}\right) d t \\
& +\frac{\psi_{t}}{\eta_{t}}\left(\sigma+\sigma_{Q, t}\right) d W_{t} \\
= & \left(d r_{f, t}+\gamma i_{t}-T_{t}+\frac{\psi_{t}}{\eta_{t}}\left(\sigma_{c h, t}-\sigma_{\theta, t}\right)\left(\sigma+\sigma_{Q, t}\right)-\frac{d \zeta_{b, t}}{N_{b, t}}\right) d t+\frac{\psi_{t}}{\eta_{t}}\left(\sigma+\sigma_{Q, t}\right) d W_{t}
\end{aligned}
$$

The law of motion for the value of the aggregate capital stock is

$$
\frac{d\left(Q_{t} K_{t}\right)}{Q_{t} K_{t}}=\left(\mu_{Q, t}+\Phi\left(\imath_{t}\right)-\delta+\sigma \sigma_{Q, t}\right) d t+\left(\sigma+\sigma_{Q, t}\right) d W_{t}
$$

Because banks' asset pricing condition always holds in equilibrium, we may write

$$
\mu_{Q, t}=d r_{f, t}+\left(\sigma_{c h, t}-\sigma_{\theta, t}\right)\left(\sigma+\sigma_{Q, t}\right)+\gamma i_{t}-\frac{a_{b}-\imath_{t}}{Q_{t}}-\left(\Phi\left(\imath_{t}\right)-\delta\right)-\sigma \sigma_{Q, t}
$$


Substituting into the law of motion for the value of capital

$$
\begin{aligned}
\frac{d\left(Q_{t} K_{t}\right)}{Q_{t} K_{t}}= & \left(d r_{f, t}+\left(\sigma_{c h, t}-\sigma_{\theta, t}\right)\left(\sigma+\sigma_{Q, t}\right)+\gamma i_{t}-\frac{a_{b}-\boldsymbol{\imath}_{t}}{Q_{t}}-\left(\Phi\left(\boldsymbol{\imath}_{t}\right)-\delta\right)-\sigma \sigma_{Q, t}+\Phi\left(\boldsymbol{l}_{t}\right)-\delta+\sigma \sigma_{Q, t}\right) d t \\
& +\left(\sigma+\sigma_{Q, t}\right) d W_{t} \\
= & \left(d r_{f, t}+\left(\sigma_{c h, t}-\sigma_{\theta, t}\right)\left(\sigma+\sigma_{Q, t}\right)+\gamma i_{t}-\frac{a_{b}-\boldsymbol{\imath}_{t}}{Q_{t}}\right) d t+\left(\sigma+\sigma_{Q, t}\right) d W_{t}
\end{aligned}
$$

By Ito's quotient rule,

$$
\frac{d\left(1 /\left(Q_{t} K_{t}\right)\right)}{1 /\left(Q_{t} K_{t}\right)}=\left(\left(\sigma+\sigma_{Q, t}\right)^{2}-d r_{f, t}-\left(\sigma_{c h, t}-\sigma_{\theta, t}\right)\left(\sigma+\sigma_{Q, t}\right)-\gamma i_{t}+\frac{a_{b}-\imath_{t}}{Q_{t}}\right) d t-\left(\sigma+\sigma_{Q, t}\right) d W_{t}
$$

Using Ito's product rule,

$$
\begin{aligned}
\frac{d \eta_{t}}{\eta_{t}}= & \left(d r_{f, t}+\gamma i_{t}-T_{t}+\frac{\psi_{t}}{\eta_{t}}\left(\sigma_{c h, t}-\sigma_{\theta, t}\right)\left(\sigma+\sigma_{Q, t}\right)-\frac{d \zeta_{b, t}}{N_{b, t}}\right) d t \\
& +\left(\left(\sigma+\sigma_{Q, t}\right)^{2}-d r_{f, t}-\left(\sigma_{c h, t}-\sigma_{\theta, t}\right)\left(\sigma+\sigma_{Q, t}\right)-\gamma i_{t}+\frac{a_{b}-\iota_{t}}{Q_{t}}\right) d t \\
& -\frac{\psi_{t}}{\eta_{t}}\left(\sigma+\sigma_{Q, t}\right)^{2} d t+\left(\frac{\psi_{t}}{\eta_{t}}-1\right)\left(\sigma+\sigma_{Q, t}\right) d W_{t}
\end{aligned}
$$

The drift simplifies to

$$
\mu_{\eta, t}=\left(\frac{\psi_{t}}{\eta_{t}}-1\right)\left(\left(\sigma_{c h, t}-\sigma_{\theta, t}\right)-\left(\sigma+\sigma_{Q, t}\right)\right)\left(\sigma+\sigma_{Q, t}\right)+\frac{a_{b}}{Q_{t}}-T_{t}-\frac{d \zeta_{b, t}}{N_{b, t}}
$$

Define $d \Xi_{t} \equiv d \zeta_{b, t} / N_{b, t}$ as a control creating an upper reflecting barrier. The drift and volatility of $d \eta_{t} / \eta_{t}$ now match 13 .

For the remainder of the proofs, time subscripts are suppressed unless required for clarity.

Proof of Proposition 3 . To derive Lemma 1, we first conjectured that $\theta$ and $Q$ are diffusions. We now verify these conjectures by applying Ito's lemma to write $\theta$ and $Q$ as functions of $\eta$. By Ito's 
lemma

$$
\begin{aligned}
\frac{d Q}{Q} & =\left(\frac{Q^{\prime}}{Q} \mu_{\eta} \eta+\frac{1}{2} \frac{Q^{\prime \prime}}{Q}\left(\sigma_{\eta} \eta\right)^{2}\right) d t+\frac{Q^{\prime}}{Q} \sigma_{\eta} \eta d W_{t} \\
\frac{d \theta}{\theta} & =\left(\frac{\theta^{\prime}}{\theta} \mu_{\eta} \eta+\frac{1}{2} \frac{\theta^{\prime \prime}}{\theta}\left(\sigma_{\eta} \eta\right)^{2}\right) d t+\frac{\theta^{\prime}}{\theta} \sigma_{\eta} \eta d W_{t}
\end{aligned}
$$

The boundary conditions for $\theta$ at $\eta^{*}$ are straightforward. Banks' first-order condition for $d \zeta$ implies $\theta\left(\eta^{*}\right)=1$. Since $d \Xi$ creates a reflecting barrier at $\eta^{*}$, smooth-pasting implies $\theta^{\prime}\left(\eta^{*}\right)=0$.

Market-clearing conditions pin down the behavior of $Q$. Aggregate household consumption is

$$
r\left(N_{h}+\theta N_{b}\right)=r(1-\eta+\theta \eta) Q K
$$

Market-clearing for consumption requires

$$
r(1-\eta+\theta \eta) Q K=\left(\left(a_{b}-a_{h}\right) \psi+a_{h}-\imath\right) K
$$

When $\eta=0$, households own all capital. The price of capital must satisfy

$$
\underline{Q}=\frac{a_{h}-\imath(\underline{Q})}{r}
$$

where $\imath(\underline{Q})$ make explicit the depencence of $\imath$ on $Q$ due to Tobin's q. When $\eta=\eta^{*}, \theta\left(\eta^{*}\right)=1$ implies that aggregate household consumption is

$$
r\left(1-\eta^{*}+\theta\left(\eta^{*}\right) \eta^{*}\right) Q K=r\left(1-\eta^{*}+\eta^{*}\right)=r Q K
$$

Banks will also own all capital at $\eta^{*}$, hence

$$
\bar{Q}=\frac{a_{b}-\imath(\bar{Q})}{r}
$$

To obtain the boundary condition for $Q^{\prime}\left(\eta^{*}\right)$, notice that $\psi$ will equal 1 over some interval $\left[\bar{\eta}, \eta^{*}\right]$, 
where $\bar{\eta}<\eta^{*}$. Then the derivative of the market-clearing condition for capital with respect to $\eta$ is

$$
\begin{gathered}
Q^{\prime}\left(\eta^{*}\right)\left(1-\eta^{*}+\theta\left(\eta^{*}\right) \eta^{*}\right)+Q\left(\eta^{*}\right)\left(\theta^{\prime}\left(\eta^{*}\right) \eta^{*}+\theta\left(\eta^{*}\right)-1\right)=-\iota^{\prime}\left(Q\left(\eta^{*}\right)\right) Q^{\prime}\left(\eta^{*}\right) \\
Q^{\prime}\left(\eta^{*}\right)\left(1-\eta^{*}+\eta^{*}\right)+Q\left(\eta^{*}\right)(0+1-1)=-\iota^{\prime}\left(Q\left(\eta^{*}\right)\right) Q^{\prime}\left(\eta^{*}\right) \\
Q^{\prime}\left(\eta^{*}\right)\left(1+\iota^{\prime}\left(Q\left(\eta^{*}\right)\right)\right)=0 .
\end{gathered}
$$

The properties of the investment technology $\Phi$ imply $\imath^{\prime}\left(Q\left(\eta^{*}\right)\right) \neq-1$, hence $Q^{\prime}\left(\eta^{*}\right)=0$.

Finally, the boundary condition $\lim _{\eta \rightarrow 0^{+}} \theta(\eta)=\infty$ holds because if a bank has capital when $\eta$ is identically zero, then that bank can acquire arbitrarily high returns. In particular, $\eta=0$ is an absorbing equilibrium. If $\eta$ reaches 0 , then $Q$ will remain forever at $\underline{Q}$. Under the assumption that interest rates are sufficiently near $\eta=0$, a bank with an infinitesimal quantity of capital at $\eta=0$ faces the excess returns

$$
\frac{a_{b}-\imath}{\underline{Q}}+\Phi(\imath)-\delta-d r_{f}-L P>\frac{a_{h}-\imath}{\underline{Q}}+\Phi(\imath)-\delta-d r_{f}=\sigma_{c h} \sigma=\sigma^{2}
$$

Leverage does not reduce a bank's excess returns because the bank is infinitesimal. Therefore, the bank can borrow as much as it wants and obtain arbitrarily high returns, resulting in an infinite value function.

The boundary conditions for $\theta$ require it to be decreasing for at least a positive-measure subset of $\left[0, \eta^{*}\right]$. When the tax rate on bank equity $T$ is sufficiently high, the equilibrium ODE for $\theta$ will satisfy $\theta^{\prime}(\cdot)<0$ and $\theta^{\prime \prime}(\cdot)>0$ over $\left[0, \eta^{*}\right]$.

Solving equilibrium with leverage constraints. Suppose the government specifies an exogenous leverage constraint policy $L(\eta)$ and requires bank leverage ${ }^{16}$ to satisfy

$$
\frac{\psi}{\eta}-1 \leq L(\eta)
$$

If leverage constraints bind, then banks' asset pricing condition (10) may not bind, which changes

\footnotetext{
${ }^{16}$ The leverage constraint applies to individual banks. Because the model admits a representative agent for banks, we directly specify the leverage constraint on the representative bank to economize on exposition.
} 
the law of motion for $\eta$. However, if banks are leverage constrained, then it must be the case that $\psi<1$, hence households' asset pricing condition (11) must bind with equality. This condition implies

$$
\frac{-\imath}{Q}+\Phi(\imath)-\delta+\mu_{Q}+\sigma \sigma_{Q}-d r_{f}=\sigma_{c h}\left(\sigma+\sigma_{Q}\right)-\frac{a_{h}}{Q}
$$

so

$$
\mathbb{E}\left[d r_{b}\right]-d r_{f}=\frac{a_{b}}{Q}-\frac{\imath}{Q}+\Phi(\imath)-\delta+\mu_{Q}+\sigma \sigma_{Q}-d r_{f}=\frac{a_{b}-a_{h}}{Q}+\sigma_{c h}\left(\sigma+\sigma_{Q}\right)
$$

Banks’ aggregate equity evolves according to

$$
\frac{d N_{b, t}}{N_{b, t}}=\left(d r_{f, t}-\gamma\left(\frac{\psi_{t}}{\eta_{t}}-1\right) i_{t}-T_{t}+\frac{\psi_{t}}{\eta_{t}}\left(\frac{a_{b}-a_{h}}{Q_{t}}+\sigma_{c h, t}\left(\sigma+\sigma_{Q, t}\right)\right)-\frac{d \zeta_{b, t}}{N_{b, t}}\right) d t+\frac{\psi_{t}}{\eta_{t}}\left(\sigma+\sigma_{Q, t}\right) d W_{t}
$$

The aggregate wealth process $Q_{t} K_{t}$ also evolves differently when leverage constraints bind. The law of motion is

$$
\frac{d\left(Q_{t} K_{t}\right)}{Q_{t} K_{t}}=\left(\mu_{Q, t}+\Phi\left(l_{t}\right)-\delta+\sigma \sigma_{Q, t}\right) d t+\left(\sigma+\sigma_{Q, t}\right) d W_{t}
$$

and by Ito's quotient rule,

$$
\frac{d\left(1 /\left(Q_{t} K_{t}\right)\right)}{1 /\left(Q_{t} K_{t}\right)}=\left(\left(\sigma+\sigma_{Q, t}\right)^{2}-\mu_{Q, t}-\left(\Phi\left(l_{t}\right)-\delta\right)-\sigma \sigma_{Q, t}\right) d t-\left(\sigma+\sigma_{Q, t}\right) d W_{t}
$$

Households' asset pricing condition implies

$$
-\mu_{Q, t}-\left(\Phi\left(\imath_{t}\right)-\delta-\sigma \sigma_{Q, t}=\frac{a_{h}-\imath_{t}}{Q}-d r_{f}-\sigma_{c h, t}\left(\sigma+\sigma_{Q}\right),\right.
$$

hence

$$
\frac{d\left(1 /\left(Q_{t} K_{t}\right)\right)}{1 /\left(Q_{t} K_{t}\right)}=\left(\left(\sigma+\sigma_{Q, t}\right)^{2}+\frac{a_{h}-\imath_{t}}{Q_{t}}-d r_{f, t}-\sigma_{c h, t}\left(\sigma+\sigma_{Q, t}\right)\right) d t-\left(\sigma+\sigma_{Q, t}\right) d W_{t} .
$$


By Ito's product rule,

$$
\begin{aligned}
\frac{d \eta_{t}}{\eta_{t}}= & \left(d r_{f, t}-\frac{\kappa}{m}\left(\frac{\psi_{t}}{\eta_{t}}-1\right) i_{t}-T_{t}+\frac{\psi_{t}}{\eta_{t}}\left(\frac{a_{b}-a_{h}}{Q_{t}}+\sigma_{c h, t}\left(\sigma+\sigma_{Q}\right)\right)-\frac{d \zeta_{b, t}}{N_{b, t}}\right) d t+\frac{\psi_{t}}{\eta_{t}}\left(\sigma+\sigma_{Q, t}\right) d W_{t} \\
& -\frac{\psi_{t}}{\eta_{t}}\left(\sigma+\sigma_{Q, t}\right)^{2} d t+\left(\left(\sigma+\sigma_{Q, t}\right)^{2}+\frac{a_{h}-l_{t}}{Q_{t}}-d r_{f, t}-\sigma_{c h, t}\left(\sigma+\sigma_{Q, t}\right)\right) d t-\left(\sigma+\sigma_{Q, t}\right) d W_{t} \\
= & \left(\frac{\psi_{t}}{\eta_{t}} \frac{a_{b}}{Q_{t}}-\left(\frac{\psi_{t}}{\eta_{t}}-1\right) \frac{a_{h}}{Q_{t}}-\frac{\boldsymbol{l}_{t}}{Q}-\frac{\kappa}{m}\left(\frac{\psi_{t}}{\eta_{t}}-1\right) i_{t}-T_{t}-\frac{d \zeta_{b, t}}{N_{b, t}}\right) d t \\
& +\left(\left(\frac{\psi_{t}}{\eta_{t}}-1\right) \sigma_{c h, t}\left(\sigma+\sigma_{Q, t}\right)-\left(\frac{\psi_{t}}{\eta_{t}}-1\right)\left(\sigma+\sigma_{Q, t}\right)^{2}\right) d t+\left(\frac{\psi_{t}}{\eta_{t}}-1\right)\left(\sigma+\sigma_{Q, t}\right) d W_{t} \\
= & \left(\frac{\psi_{t}}{\eta_{t}} \frac{a_{b}}{Q_{t}}-\left(\frac{\psi_{t}}{\eta_{t}}-1\right) \frac{a_{h}}{Q_{t}}-\frac{\boldsymbol{l}_{t}}{Q}-\frac{\kappa}{m}\left(\frac{\psi_{t}}{\eta_{t}}-1\right) i_{t}-T_{t}-\frac{d \zeta_{b, t}}{N_{b, t}}\right) d t \\
& +\left(\frac{\psi_{t}}{\eta_{t}}-1\right)\left(\sigma_{c h, t}-\left(\sigma+\sigma_{Q, t}\right)\right)\left(\sigma+\sigma_{Q, t}\right) d t+\left(\frac{\psi_{t}}{\eta_{t}}-1\right)\left(\sigma+\sigma_{Q, t}\right) d W_{t} .
\end{aligned}
$$

Thus, $\mu_{\eta}$ and $\sigma_{\eta}$ when leverage constraints bind are given by

$$
\begin{aligned}
& \mu_{\eta}=\frac{\psi}{\eta} \frac{a_{b}}{Q}-\left(\frac{\psi}{\eta}-1\right) \frac{a_{h}}{Q}-\frac{\imath}{Q}-\frac{\kappa}{m}\left(\frac{\psi}{\eta}-1\right) i-T-\Xi+\left(\frac{\psi}{\eta}-1\right)\left(\sigma_{c h}-\left(\sigma+\sigma_{Q}\right)\right)\left(\sigma+\sigma_{Q}\right) \\
& \sigma_{\theta}=\left(\frac{\psi}{\eta}-1\right)\left(\sigma+\sigma_{Q}\right)
\end{aligned}
$$

Banks' Bellman equation also changes because they cannot obtain first-order optimality for their portfolio choice. Prior to substitution of the first-order condition for $x_{b, t}$, their Bellman equation is

$$
T_{t}=\mu_{\theta, t}-\sigma_{c h, t} \sigma_{\theta, t}+x_{b, t}\left(\mathbb{E}\left[d r_{b, t}\right]-d r_{f, t}+\left(\sigma_{\theta, t}-\sigma_{c h, t}\right)\left(\sigma+\sigma_{Q, t}\right)\right)-\frac{\kappa}{m} x_{b, t} i_{t}+\frac{\kappa}{m} i_{t}
$$

Using households' asset pricing condition, banks’ Bellman equation becomes

$$
\begin{aligned}
T_{t} & =\mu_{\theta, t}-\sigma_{c h, t} \sigma_{\theta, t}+x_{b, t}\left(\frac{a_{b}-a_{h}}{Q_{t}}+\sigma_{c h, t}\left(\sigma+\sigma_{Q, t}\right)+\left(\sigma_{\theta, t}-\sigma_{c h, t}\right)\left(\sigma+\sigma_{Q, t}\right)\right)-\frac{\kappa}{m} x_{b, t} i_{t}+\frac{\kappa}{m} i_{t} \\
& =\mu_{\theta, t}-\sigma_{c h, t} \sigma_{\theta, t}+\frac{\kappa}{m} i_{t}+x_{b, t}\left(\frac{a_{b}-a_{h}}{Q_{t}}+\sigma_{\theta, t}\left(\sigma+\sigma_{Q, t}\right)-\frac{\kappa}{m} i_{t}\right) .
\end{aligned}
$$


Re-arranging yields the new equation for $\mu_{\theta}$ :

$$
\mu_{\theta}=T+\sigma_{c h} \sigma_{\theta}-\frac{\kappa}{m} i-\frac{\psi}{\eta}\left(\frac{a_{b}-a_{h}}{Q}-\left(-\sigma_{\theta}\left(\sigma+\sigma_{Q}\right)+\frac{\kappa}{m} i\right)\right)
$$

To summarize, when leverage constraints bind, $\mu_{\eta}, \sigma_{\eta}$, and $\mu_{\theta}$ are given by the equations derived above. The remaining quantities can be obtained using the same procedures as when banks are not constrained. Furthermore, when leverage constraints do not bind, $\mu_{\eta}, \sigma_{\eta}$, and $\mu_{\theta}$ are given by the exact same equations as before. Despite this fact, the global solution will change because the behavior of $\theta$ and $Q$ in the regions of $\eta$ for which the leverage constraint binds will be different, which affects their behavior elsewhere.

Proof of Friedman Rule, Proposition 4 . When banks can freely issue equity, then equilibrium is stationary with constant asset price $Q^{*}$, constant capital allocation (banks hold all capital), and no endogenous risk or instability, implying banks do not have a required risk premium. Maximizing the asset price is therefore sufficient to maximize welfare. From equation 10 we have

$$
Q^{*}=\frac{a_{b}-\imath\left(Q^{*}\right)}{r^{*}+\sigma^{2}+L P^{*}-\Phi\left(\imath\left(Q^{*}\right)\right)+\delta}
$$

where $r^{*}$ is the real interest rate and all stochastic terms are zero. It therefore follows immediately that $Q^{*}$ is maximized for $L P=0$ since the risk-free rate is not affected by nominal rates, and the zero lower bound prevents $L P<0$.

\section{A.2 Numerical Algorithm}

In this section, we show that equilibrium can be characterized as a system of differential equations for $\theta$ and $Q$. To handle the endogeneity of the state space boundary $\eta^{*}$, we reformulate the boundary value problem as a least-squares problem. For this section, we suppress time subscripts unless required for clarity. 


\section{A.2.1 No Leverage Constraints}

From Proposition 2, the drift of $\theta$ is $\mu_{\theta}=T+\sigma_{c h} \sigma_{\theta}-\gamma i$. Since $\theta$ decreases with $\eta$, a smaller drift of $\theta$ implies that $\theta$, in expectation, moves toward larger values and bad times at a slower rate, reflecting the partial equilibrium intuition that higher interest rates should disincentivize excessive risk-taking. By Ito's lemma, we also have that

$$
\mu_{\theta, t}=\frac{\theta^{\prime}}{\theta} \eta_{t} \mu_{\eta, t}+\frac{1}{2} \frac{\theta^{\prime \prime}}{\theta} \eta_{t}^{2} \sigma_{\eta, t}^{2}
$$

Setting these two equations equal to each other yields a second-order ODE in $\eta_{t}$ for $\theta$.

The price of capital and the allocation of capital are related by the market-clearing condition for consumption

$$
r W_{h}=\left(a_{b} \psi+a_{h}(1-\psi)-\imath\right) K
$$

Substitution and dividing by $K$ yields

$$
r Q(1+(\theta-1) \eta)=\left(a_{b}-a_{h}\right) \psi+a_{h}-\imath
$$

The functional form for internal investment (16) implies

$$
Q=\frac{\left(a_{b}-a_{h}\right) \psi+a_{h}+\frac{1}{\varepsilon}}{r(1+(\theta-1) \eta)+\frac{1}{\varepsilon}}
$$

We obtain a differential equation for $Q$ by using the equilibrium asset pricing condition (12). When $\psi=1,12$ is slack, and $Q^{\prime}$ can be obtained by directly differentiating with respect to $\eta$. When $\psi<1,(12)$ binds with equality and can be re-arranged to

$$
\sigma_{Q}=\sqrt{\frac{\frac{a_{b}-a_{h}}{Q}-L P_{t}}{-\frac{\theta^{\prime}}{\theta}(\psi-\eta)}}-\sigma
$$


Recall that

$$
\sigma_{\eta}=\left(\frac{\psi}{\eta}-1\right)\left(\sigma+\sigma_{Q}\right)
$$

By Ito’s lemma,

$$
\sigma_{Q}=\frac{Q^{\prime}}{Q} \sigma_{\eta} \eta
$$

hence

$$
Q^{\prime}=\frac{Q \sigma_{Q}}{\sigma_{\eta} \eta} .
$$

Therefore, equilibrium is characterized by a solution to the system of differential equations

$$
\begin{aligned}
& Q^{\prime}= \begin{cases}\frac{Q \sigma_{Q}}{\sigma_{\eta} \eta} & \text { if } \psi<1, \\
-\frac{r Q\left(\theta^{\prime} \eta+(\theta-1)\right)}{r(1+(\theta-1) \eta)+\frac{1}{\varepsilon}} & \text { if } \psi=1,\end{cases} \\
& \theta^{\prime \prime}=\frac{2}{\left(\sigma_{\eta} \eta\right)^{2}}\left(\theta \mu_{\theta}-\theta^{\prime} \mu_{\eta} \eta\right),
\end{aligned}
$$

where $\psi \leq 1$ and can be calculated from $Q$ using $(23)$.

\section{A.2.2 Leverage Constraints}

To implement leverage constraints numerically, during integration of $\theta$ and $Q$, we add a check for whether the leverage constraint $L(\eta)$ is violated by the $\psi$ consistent with the proposed $\theta$ and $Q$ according to market-clearing for consumption. If $\psi$ exceeds the leverage constraint, then we set $\psi=\eta(L(\eta)+1)$ and calculate the derivative $Q^{\prime}$ by directly differentating the market-clearing condition for consumption instead of using banks' asset pricing condition. Given sufficiently small step sizes, continuity of the numerical solutions guarantee that the approximations to $\theta$ and $Q$ obey the leverage constraint.

A specific leverage constraint of interest is the incentive compatible leverage constraint used by 
Van der Ghote (2020). We assume each household delegate management of their bank to another agent, and banks cannot accept deposits from their owning household. This delegation is subject to a limited enforcement friction. The agent managing a bank can divert a portion $1 / \alpha$ of their assets immediately after raising deposits from households. Should an agent do so, then that agent's bank immediately shuts down but they keep the assets they stole. As a result, a bank's portfolio choice has the following constraint:

$$
\frac{1}{\alpha} x_{b} n_{b} \leq \theta n_{b}
$$

The left-hand side is the value of the assets a bank manager could steal, and the right-hand side is the bank's value if the bank manager continues to operate the bank. After simplification, this constraint becomes

$$
x_{b} \leq \alpha \theta
$$

This inequality asserts that bank leverage cannot succeed a multiple of the marginal value of a bank's equity. Otherwise, the bank manager would strictly benefit by diverting assets and closing down the bank.

For our model, this form of the constraint causes numerical problems. We instead consider the following variant:

$$
x_{b} \leq \alpha \theta+1,
$$

which implies

$$
L \leq \alpha \theta \text {. }
$$




\section{A.2.3 Least-Squares Problem}

The boundary conditions for $Q$ at $\eta=0$ and $\bar{\eta}$ can be calculated directly from the model's parameters. The boundary condition for $\theta$ at $\bar{\eta}$ is also known. Since $\lim _{\eta \rightarrow 0^{+}} \theta(\eta)=\infty$, it must be the case that $\lim _{\eta \rightarrow 0^{+}} \theta^{\prime}(\eta)=-\infty$. Due to the singularity at $\eta=0$, we solve over a grid slightly perturbed away from 0 to some $\underline{\eta}$, so we have to guess $\theta(\underline{\text { eta }})$ and $\theta^{\prime}(\underline{\eta})$. In practice, the choice of $\theta^{\prime}(\underline{\eta})$ does not affect global dynamics as long as it is a sufficiently negative number. We fix $\theta^{\prime}(\underline{\eta})$ at some guess and treat $\theta(\underline{\eta})$ as a control in a least-squares problem. Given $\theta(\underline{\eta})$ and $\theta^{\prime}(\underline{\eta})$, we can integrate the equilibrium system of differential equations as if it is an initial-value problem with the boundary conditions at $\bar{\eta}$ as terminating events:

1. $\theta(\eta)<1$,

2. $\theta^{\prime}(\eta)>0$,

3. $Q(\eta)>\bar{Q}$.

The first and third terminating events imply each other when we have found a solution, but in practice, omitting the third boundary condition makes the numerical algorithm perform better.

Our residual function is just a weighted sum of the squared errors in the boundary conditions:

$$
F(\theta(\underline{\eta}))=w^{T}\left(\begin{array}{c}
\theta(\bar{\eta})-1 \\
\theta^{\prime}(\bar{\eta}) \\
Q-\bar{Q}
\end{array}\right) w
$$

where $w$ is primarily chosen to renormalize the size of the errors. With this residual function and an initial guess for $\theta(\underline{\eta})$, we can use any standard algorithm for least-squares minimization, such as the interior-point method or sequential quadratic programming, both of which are available through MATLAB's fmincon function. To reduce computational time, we start with a bisection 
search to find an interval in which $\theta(\underline{\eta})$ should belong. If the minimizing $\theta(\underline{\eta})$ implies a residual function sufficiently close to zero, then a solution has been found.

To summarize:

1. Select $\underline{\eta}$ close to zero, set $\theta^{\prime}(\underline{\eta})$ to a very negative number (e.g. $\left.-5 \times 10^{4}\right)$, and guess $\theta(\underline{\eta})$.

2. Integrate the differential equations for $\theta$ and $Q$ until one of the terminating events occurs:

- $\theta(\eta)<1$,

- $\theta^{\prime}(\eta)>0$.

3. Calculate the residuals at the terminating $\eta$.

4. Use a least-squares solver to find a minimizing $\theta(\underline{\eta})$. If the residual are sufficiently close to zero, then a solution has been found.

\section{A.2.4 Welfare}

To compute welfare, we solve the HJB for the representative household. Because households have $\log$ utility, the representative household's value function takes the form

$$
V\left(W_{h}\right)=\frac{\log \left(W_{h}\right)}{r}+h(\eta)
$$

Plugging in for household wealth, we obtain

$$
V(\eta)=\frac{\log (Q K(1+(\theta-1) \eta))}{r}+h(\eta)=\frac{\log (Q)}{r}+\frac{\log (K)}{r}+\frac{\log (1+(\theta-1) \eta)}{r}+h(\eta) .
$$

Define $H(\eta)=\log (Q) / r+h(\eta)$. Then the value function simplifies to

$$
V(\eta)=\frac{\log (K)}{r}+\frac{\log (1+(\theta-1) \eta)}{r}+H(\eta)
$$


The HJB is

$$
\begin{aligned}
r\left(\frac{\log (K)}{r}+\frac{\log (1+(\theta-1) \eta)}{r}+H(\eta)\right) & =\log \left(C_{h}\right)+E[d V] \\
\log (K)+\log (1+(\theta-1) \eta)+r H & =\log (r Q K(1+(\theta-1) \eta))+\mathbb{E}[d V] \\
r H & =\log (r Q)+\mathbb{E}[d V] .
\end{aligned}
$$

It remains to characterize $d V$. Recall that

$$
V=\frac{\log (K)}{r}+\frac{\log (1+(\theta-1) \eta)}{r}+H(\eta) .
$$

We may write

$$
\begin{aligned}
d(1+(\theta-1) \eta) & =d(\theta \eta-\eta)=\left(\theta \eta\left(\mu_{\theta}+\mu_{\eta}+\sigma_{\theta} \sigma_{\eta}\right)-\eta \mu_{\eta}\right) d t+\left(\theta \eta\left(\sigma_{\theta}+\sigma_{\eta}\right)-\eta \sigma_{\eta}\right) d W_{t} \\
& =\left(\theta \eta\left(\mu_{\theta}+\sigma_{\theta} \sigma_{\eta}\right)+(\theta-1) \eta \mu_{\eta}\right) d t+\left(\theta \eta \sigma_{\theta}+(\theta-1) \eta \sigma_{\eta}\right) d W_{t} \\
\frac{d(1+(\theta-1) \eta)}{1+(\theta-1) \eta} & =\left(\frac{\theta \eta}{1+(\theta-1) \eta}\left(\mu_{\theta}+\sigma_{\theta} \sigma_{\eta}\right)+\frac{(\theta-1) \eta}{1+(\theta-1) \eta} \mu_{\eta}\right) d t+\frac{\theta \eta \sigma_{\theta}+(\theta-1) \eta \sigma_{\eta}}{1+(\theta-1) \eta} d W_{t}
\end{aligned}
$$

By Ito's lemma, for any Ito process $d X$,

$$
d \log (X)=\frac{d X}{X}-\frac{(d X)^{2}}{2 X^{2}}
$$

Therefore,

$$
\begin{aligned}
\mathbb{E}[d V]= & \frac{1}{r} \mathbb{E}[d \log (K)]+\frac{1}{r} \mathbb{E}[d \log (1+(\theta-1) \eta)]+\mathbb{E}[d H] \\
= & \frac{1}{r}\left\{\Phi(Q)-\delta-\frac{1}{2} \sigma^{2}\right\}+\frac{1}{r}\left\{\frac{\theta \eta\left(\mu_{\theta}+\sigma_{\theta} \sigma_{\eta}\right)+(\theta-1) \eta \mu_{\eta}}{1+(\theta-1) \eta}-\frac{\left(\theta \eta \sigma_{\theta}+(\theta-1) \eta \sigma_{\eta}\right)^{2}}{2(1+(\theta-1) \eta)^{2}}\right\} \\
& +H^{\prime} \eta \mu_{\eta}+\frac{1}{2} H^{\prime \prime} \sigma_{\eta}^{2} \eta^{2}
\end{aligned}
$$


Plugging this quantity into the HJB yields a second-order differential equation for $H$ :

$$
\begin{aligned}
r H= & \log (r Q)+\frac{1}{r}\left\{\Phi(Q)-\frac{1}{2} \sigma^{2}\right\}+\frac{1}{r}\left\{\frac{\theta \eta\left(\mu_{\theta}+\sigma_{\theta} \sigma_{\eta}\right)+(\theta-1) \eta \mu_{\eta}}{1+(\theta-1) \eta}-\frac{\left(\theta \eta \sigma_{\theta}+(\theta-1) \eta \sigma_{\eta}\right)^{2}}{2(1+(\theta-1) \eta)^{2}}\right\} \\
& +H^{\prime} \eta \mu_{\eta}+\frac{1}{2} H^{\prime \prime} \sigma_{\eta}^{2} \eta^{2}
\end{aligned}
$$

This can be re-arranged into the explicit differential equation

$$
H^{\prime \prime}=\frac{2}{\left(\sigma_{\eta} \eta\right)^{2}}\left(r H-H^{\prime} \eta \mu_{\eta}-\mathscr{I}\right)
$$

where $\mathscr{I}$ is the inhomogeneous part of the differential equation

$$
\mathscr{I}=\log (r Q)+\frac{1}{r}\left\{\Phi(Q)-\frac{1}{2} \sigma^{2}\right\}+\frac{1}{r}\left\{\frac{\theta \eta\left(\mu_{\theta}+\sigma_{\theta} \sigma_{\eta}\right)+(\theta-1) \eta \mu_{\eta}}{1+(\theta-1) \eta}-\frac{\left(\theta \eta \sigma_{\theta}+(\theta-1) \eta \sigma_{\eta}\right)^{2}}{2(1+(\theta-1) \eta)^{2}}\right\}
$$

This differential equation is linear in $H$.

To calculate welfare differences in consumption equivalents, define welfare under a baseline scenario as

$$
V^{(0)}=\max \mathbb{E}_{0}\left[\int_{0}^{\infty} e^{-r t} \log \left(C_{h, t}^{(0)}\right) d t\right]
$$

Define $V^{(1)}$ similarly, and let it denote household welfare under an alternative scenario. The consumption-equivalent increase in welfare is the quantity $\phi^{+}$, which satisfies

$$
\begin{aligned}
V^{(1)} & =\max \mathbb{E}_{0}\left[\int_{0}^{\infty} e^{-r t} \log \left(\left(1+\phi^{+}\right) C_{h, t}^{(0)}\right) d t\right]=\max \mathbb{E}_{0}\left[\int_{0}^{\infty} e^{-r t}\left(\log \left(1+\phi^{+}\right)+\log \left(C_{h, t}^{(0)}\right) d t\right]\right. \\
& =\log \left(1+\phi^{+}\right) \int_{0}^{\infty} e^{-r t} d t+V^{(0)}=-\left.\frac{\log \left(1+\phi^{+}\right)}{r} e^{-r t}\right|_{0} ^{\infty}+V^{(0)}=\frac{\log \left(1+\phi^{+}\right)}{r}+V^{(0)}
\end{aligned}
$$

Re-arranging yields

$$
\phi^{+}=\exp \left(r\left(V^{(1)}-V^{(0)}\right)\right)-1
$$


Similarly, if household welfare decreases under the alternative scenario and $\phi^{-}$is the consumptionequivalent decrease, then

$$
\phi^{-}=1-\exp \left(r\left(V^{(1)}-V^{(0)}\right)\right)
$$

Thus, the consumption-equivalent difference in welfare is

$$
\phi=\left|\exp \left(r\left(V^{(1)}-V^{(0)}\right)\right)-1\right|
$$

\section{A.2.5 Stationary Distribution}

If a stationary distribution exists, then the stationary probability density function $g(\eta)$ solves a Kolmogorov forward equation. Following Brunnermeier and Sannikov (2014), we simplify the Kolmogorov forward equation to a first-order ODE, which can be solved as an initial value problem and renormalized to satisfy $\int_{0}^{\eta^{*}} g(\eta) d \eta=1$.

\section{A.2.6 Boundary Macroprudential Policies}

This section derives the boundary conditions for macroprudential policies which change the equilibrium boundary conditions.

Dividend Subsidy/Tax When banks issue a dollar of dividends, the government also pays out $\Delta_{S D}$ dollars and funds these payouts by lump sum taxes on households. If $\Delta_{S D}<0$, then banks are getting taxed when they issue dividends, and households receive lump-sump payments. We model this policy by modifying banks' objective function to be

$$
\mathbb{E}\left[\int_{0}^{\infty} e^{-r t}\left(\left(1+\Delta_{S D}\right) d \zeta_{t}^{b} \mathbb{I}_{d \zeta_{t}^{b} \geq 0}+d \zeta_{t}^{b} \mathbb{I}_{d \zeta<0}\right)\right]
$$

This objective function implies $\theta(\bar{\eta})=1+\Delta_{S D}$. The smooth-pasting condition becomes

$$
\theta^{\prime}(\bar{\eta})=\frac{1}{\bar{\eta}}\left(1-\left(1+\Delta_{S D}\right)\right)=-\frac{\Delta_{S D}}{\bar{\eta}}
$$


since it still costs banks one unit of equity to pay dividends.

The boundary condition for $Q^{\prime}(\bar{\eta})$ remains the same. Additionally note it is still true that

$$
\theta^{\prime}(\bar{\eta}) \bar{\eta}+\theta(\bar{\eta})-1=0
$$

so $Q^{\prime}(\bar{\eta})=0$ remains true.

Tail Risk Insurance. The boundary condition $\theta(\underline{\eta})$ changes to

$$
\theta(\underline{\eta})=-\theta^{\prime}(\underline{\eta}) \underline{\eta}
$$

To derive this boundary condition, note that tail risk insurance is equivalent to a lower reflecting barrier with zero cost of reflection, hence

$$
\theta(\underline{\eta})+\theta^{\prime}(\underline{\eta}) \underline{\eta}=0
$$

Re-arranging yields $(27)$. Note that $\theta^{\prime}<0$, hence this condition is positive.

The price of capital has the new boundary condition $Q^{\prime}(\underline{\eta})=0$. We can still reformulate the boundary value problem as a least-squares problem but with $\underline{\eta}$ as an additional control. The differential equations can also still be explicitly integrated. Given a guess for $\theta(\underline{\eta})$, we can calculate $\theta^{\prime}(\underline{\eta})$, so we have the right initial values for $\theta$. For $Q$, we have the first derivative rather than $Q(0)$, but we use the fact that either $\psi<1$ or $\psi=1$. If $\psi<1$, then the asset pricing condition

$$
\frac{a_{b}-a_{h}}{Q}=-\sigma_{\theta}\left(\sigma+\sigma_{Q}\right)+\gamma i
$$

must still hold. Since $Q^{\prime}(\underline{\eta})=0, \sigma_{Q}=0$. Since

$$
\sigma_{\theta}(\underline{\eta})=\frac{\theta^{\prime}(\underline{\eta})}{\theta(\underline{\eta})}(\psi-\eta)\left(\sigma+\sigma_{Q}(\underline{\eta})\right)=\frac{\theta^{\prime}(\underline{\eta})}{\theta(\underline{\eta})}(\psi-\eta) \sigma,
$$


the value of $Q(\underline{\eta})$ consistent with $Q^{\prime}(\underline{\eta})=0$ is

$$
Q(\underline{\eta})=\frac{a_{b}-a_{h}}{-\sigma_{\theta}(\underline{\eta}) \sigma+\gamma i(\underline{\eta})}
$$

Market-clearing for consumption gives

$$
Q\left(r(1+(\theta-1) \eta)+\frac{\varepsilon_{1}}{\varepsilon_{2}}\right)=\left(a_{b}-a_{h}\right) \psi+a_{h}+\frac{1}{\varepsilon_{2}}
$$

Since $\theta(\underline{\eta})$ and $\underline{\eta}$ are taken as given, these two equations yield two equations for the two unknown $Q(\underline{\eta})$ and $\psi(\underline{\eta})$. By solving these two equations, we obtain the initial values $\left(\theta(\underline{\eta}), \theta^{\prime}(\underline{\eta}), Q(\underline{\eta})\right)$.

\section{B A Model of Monetary Policy Transmission}

In this section, we utilize the model of monetary policy transmission from Drechsler et al. (2018) to microfound the relationship between the nominal interest rate and the liquidity premium on bank deposits in our model.

\section{B.1 Monetary Policy: Nominal Rates, Inflation, and Liquidity Premia}

Following Drechsler et al. (2018), monetary policy determines the opportunity cost of holding liquid assets_-namely, central bank reserves_rather than capital (i.e., determines the liquidity premium). To capture the money multiplier of reserves, each dollar of reserves yields $m>1$ effective liquid assets. The central bank can create and withdraw reserves by exchanging government bonds through open market operations (see Drechsler et al. (2018) for implementation details).

Let $M_{t}$ be the total dollar value of reserves in the economy, and let $s_{t}$ be the value of a dollar in consumption units. Letting reserves be the numeraire, $s_{t}$ becomes the inverse price level, and the real value of liquid assets held by banks scaled by aggregate wealth is

$$
S_{t}=\frac{s_{t}(m-1) M_{t}}{Q_{t} k_{t}}
$$


The remaining liquidity is given by the value of government bonds held by the central bank, $s_{t} M_{t}$.

Inflation and the Nominal Rate We assume inflation is locally deterministic, i.e.

$$
-\frac{d s_{t}}{s_{t}}=\frac{d p_{t}}{p_{t}}=\pi_{t} d t
$$

Since the rate on deposits pins down the risk-free interest rate, the nominal interest rate is

$$
i_{t}=r-\phi_{L}+\pi_{t}
$$

Liquidity Premia The liquidity premium on reserves is the opportunity cost of holding liquid assets. Because reserves pay no interest, their return is equal to their capital gain, so the liquidity premium that deposits earn is

$$
d r_{f, t}-\frac{d s_{t}}{s_{t}}=d r_{f, t}+\pi_{t}=i_{t},
$$

which is precisely the nominal interest rate.

The government earns seigniorage from the liquid assets held by banks. To close the model, we assume the seigniorage is distributed to households, so the fraction of bank equity is unaffected by seigniorage, and the government maintains zero net worth.

Policy Implementation The implementation of an interest rate rule $i$ is the same as Drechsler et al. (2018), so we relegate the details to that paper. However, we still state the proposition here because it yields an expression satisfied by the real value of liquidity which we will use later.

Proposition 5. To implement the nominal interest rate rule $i_{t}$, the nominal supply of reserves $M_{t}$ must grow according to

$$
\frac{d M_{t}}{M_{t}}=\left(i_{t}-d r_{f, t}\right) d t+\frac{d S_{t}}{S_{t}}+\frac{d Q_{t}}{Q_{t}}+\left(\frac{d S_{t}}{S_{t}}\right)\left(\frac{d Q_{t}}{Q_{t}}\right)+\frac{d k_{t}}{k_{t}}+\left(\frac{d S_{t}}{S_{t}}+\frac{d Q_{t}}{Q_{t}}\right)\left(\frac{d k_{t}}{k_{t}}\right),
$$


and the real value of liquidity as a share of wealth satisfies

$$
S_{t}=\eta_{t} \kappa\left(x_{b, t}-1\right)
$$

\section{B.2 Banks' Problem}

Following Drechsler et al. (2018) we assume deposits are subject to funding shocks, which are modeled as a Poisson process $J_{t}$ with constant intensity $\chi . J_{t}$ is an aggregate shock, and when $J_{t}$ realizes, banks must immediately redeem a fraction $\frac{\kappa}{1+\kappa}$ of their deposits, where $\kappa>0$. Only a fraction $1-\rho \in(0,1)$ of capital's value can be recovered quickly enough to absorb a funding shock. Banks may self-insure by holding liquid assets, which can be liquidated without causing fire sales when a funding shock realizes.

Let $\left(x_{b, t}, x_{M, t}, x_{b d, t}\right)$ be portfolio weights on capital, reserves, and debt. Since the portfolio weights sum to one, we rewrite $x_{b d, t}=1-x_{b, t}-x_{M, t}$.

Formally, banks solve the problem

$$
\max _{\left\{x_{b, t}, x_{M, t} d \zeta_{t}\right\}} U_{\tau}=\mathbb{E}_{\tau}\left[\int_{\tau}^{\infty} \frac{\xi_{t}}{\xi_{\tau}} d \zeta_{t}\right]
$$

subject to

$$
\begin{gathered}
\frac{d n_{b, t}}{n_{b, t}}=d r_{f, t}-\left(x_{M, t} i_{t}+T_{t}\right) d t+x_{b, t}\left(d r_{t}^{b}-d r_{f, t} d t\right)-\frac{d \zeta_{b, t}}{n_{b, t}} \\
-\frac{\rho}{1-\rho} \max \left\{\frac{\kappa}{1+\kappa}\left(x_{b, t}+m x_{M, t}-1\right)-m x_{M, t}, 0\right\} d J_{t}, \\
n_{b, t}, x_{b, t}, x_{M, t} d \zeta_{t} \geq 0 .
\end{gathered}
$$

Banks earn the deposit rate, pay the liquidity premium on reserves, pay an exogenous tax, earn the risk premium on capital holdings, and pay dividends at rate $d \zeta_{t}$. The second line of (31) reflects the exposure of banks to funding shocks given their portfolio. Note that, unlike Drechsler et al. (2018), we abstract from government bonds and only include central bank reserves. ${ }^{17}$ Banks also

\footnotetext{
${ }^{17}$ For the equivalent net worth equation, see (A7) in the appendix of Drechsler et al. (2018) and note that $x_{M, t}$ in our
} 
do not earn seigniorage payments, which are instead distributed only to households.

Recall that in Appendix A, we solve banks' portfolio choice problem by conjecturing $\theta_{t}, c_{h, t}$, and $Q_{t}$ follow diffusion processes. Given these conjectures, we can calculate first-order conditions and derive the law of motion for the state variable $\eta_{t}$. Once we compute $d \eta_{t}$, we can apply Ito's lemma to verify our conjectures, namely that $\theta_{t}, c_{h, t}$, and $Q_{t}$ are diffusion processes in equilibrium.

The microfoundation of monetary policy transmission from Drechsler et al. (2018) can be easily placed within this solution strategy. Below, we derive a sufficient condition for the fullinsurance equilibrium, assuming our conjectures for $\theta_{t}$ and $c_{h, t}$ hold. If this sufficient condition holds, then we can rewrite the bank's portfolio choice problem as the problem stated in the main text (Section 2.2). Thus, the proofs in Appendix A still hold with this microfoundation.

Lemma 2. Suppose $\theta_{t}$ and $c_{h, t}$ are diffusion processes

$$
\begin{aligned}
\frac{d \theta_{t}}{\theta_{t}} & =\mu_{\theta, t} d t+\sigma_{\theta, t} d W_{t} \\
\frac{d c_{h, t}}{c_{h, t}} & =\mu_{c h, t} d t+\sigma_{c h, t} d W_{t} .
\end{aligned}
$$

If $\chi$ and $\rho$ are such that, for all $i_{t}$,

$$
\chi \frac{\rho}{1-\rho} \frac{\kappa}{1+\kappa} \geq L P_{t}
$$

where $L P_{t} \equiv \frac{\kappa}{m} i_{t}$ is the liquidity premium at interest rate $i_{t}$, then banks fully self-insure, and their liquidity demand is given by

$$
m x_{M, t}=\max \left\{\kappa\left(x_{b, t}-1\right), 0\right\}
$$

Proof Lemma 2 Banks' value function is $\theta_{t} n_{b, t}$. Banks also discount using the stochastic discount paper is $w_{M}$ in their paper. Since we do not have government reserves, $w_{G} \equiv 0$ so that $w_{L}=m w_{M}$. 
factor $e^{-r t} c_{h, t}^{-1}$. Under the conjectured law of motion for $\theta_{t}$, Ito's product rule implies

$$
\begin{aligned}
\frac{d\left(\theta_{t} n_{b, t}\right)}{\theta_{t} n_{b, t}}= & \left(\mu_{\theta, t}+\mu_{n b, t}+\sigma_{\theta, t} \sigma_{n b, t}\right) d t+\left(\sigma_{\theta, t}+\sigma_{n b, t}\right) d W_{t} \\
& -\frac{\rho}{1-\rho} \max \left\{\frac{\kappa}{1+\kappa}\left(x_{b, t}+m x_{M, t}-1\right)-m x_{M, t}, 0\right\} d J_{t} .
\end{aligned}
$$

After suppressing the controls, dropping the differential $d t$, and using the laws of motion for $\theta_{t} n_{b, t}$ and $c_{h, t}$, equation (20) simplifies to

$$
\begin{gathered}
r \theta_{t} n_{b, t} c_{h, t}^{-1}=\max c_{h, t}^{-1} d \zeta_{t}+\theta_{t} n_{b, t} c_{h, t}^{-1}\left(\mu_{\theta, t}+\mu_{n b, t}-\mu_{c h, t}+\sigma_{c h, t}^{2}+\sigma_{\theta, t} \sigma_{n b, t}-\sigma_{c h, t} \sigma_{n b, t}-\sigma_{c h, t} \sigma_{\theta, t}\right) \\
-\chi \frac{\rho}{1-\rho} \max \left\{\frac{\kappa}{1+\kappa}\left(x_{b, t}+m x_{M, t}-1\right)-m x_{M, t}, 0\right\} .
\end{gathered}
$$

Note that banks take $\theta_{t}$ and $c_{h, t}$ as given because the marginal value of bank equity $\theta_{t}$ will not change due to the decisions of an infinitissimal bank, and $c_{h, t}$ is not controlled by banks. Therefore, the first-order condition for $x_{M, t}$ is

$$
\begin{aligned}
0 & \leq-i_{t}-\chi \frac{\rho}{1-\rho}\left(\frac{\kappa}{1+\kappa} m-m\right) \\
i_{t} & \leq m \chi \frac{\rho}{1-\rho} \frac{1}{1+\kappa} \\
\gamma i_{t} & \leq \chi \frac{\rho}{1-\rho} \frac{\kappa}{1+\kappa} \frac{1+\kappa_{\theta, t}}{1+\kappa_{c h, t}}
\end{aligned}
$$

By our hypothesis, the FOC for $x_{M, t}$ is always satisfied. Since $i_{t}$ in equilibrium depends on $\eta_{t}$, a bounded variable, there always exist $\chi, \rho$ sufficiently large to ensure that (33) always holds.

Finally, to ensure that the max function returns zero, $x_{M, t}$ must satisfy

$$
0=\frac{\kappa}{1+\kappa}\left(x_{b, t}-1\right)-\frac{1}{1+\kappa} m x_{M, t}
$$

which implies the desired demand function.

Lemma2 implies that if $\theta_{t}$ and $c_{h, t}$ are diffusions, then equation (33) is a sufficient condition for full insurance. If banks are fully insured against funding shocks, then their equity never jumps in 
equilibrium. If their equity never jumps in equilibrium, then the marginal value of bank equity will never jump. Since $c_{h, t}=r\left(n_{h, t}+\theta n_{b, t}\right)$, household consumption wlll also never jump. Therefore, if parameters are chosen such that $(33)$ holds, then an equilibrium in which $\theta_{t}$ and $c_{h, t}$ are diffusions is consistent with a bank's optimal portfolio choice.

In a full-insurance equilibrium, we may zero out the jump term in (31). Because banks have a productive advantage, they will always be levered, so we may directly substitute $m x_{M, t}=\kappa\left(x_{b, t}-\right.$ 1) into the Bellman equation. Hence, the nominal interest rates $i_{t}$ determine the liquidity premium $L P_{t}$ in equilibrium, where $\gamma=\frac{\kappa}{m}$ in the main text.

\section{Timing the Put: Keep Powder Dry?}

Cutting rates during a crisis can substantially improve stability by providing cheap funding for banks, enabling them to quickly rebuild equity. Should central banks, therefore, cut rates early to avoid entering a crisis? Or should central banks "keep their powder dry" by waiting to cut but then cutting quickly? In a standard linearized model, what often matters the most is the level of rates, not the change in the policy rule. In contrast, because our model features non-linear dynamics, changes in rates matter more for some variables than the overall level of rates.

In a standard New Keynesian model, the optimal timing depends on the risk of hitting the zerolower bound ("ZLB"). Reifschneider and Williams (2000) find that when the ZLB is nowhere in view, one can afford to move slowly and take a "wait and see" approach to gain additional clarity about potentially adverse economic developments. But when interest rates are in the vicinity of the ZLB, central banks ought to "vaccinate" against further ills, acting quickly to lower rates at the first sign of economic distress. Our model provides complementary insights with regards to using monetary policy to target financial stability, which is not identical to the standard focus of aggregate stabilization. We find that whether the central bank should "keep their powder dry" or not depends on the extent to which the central bank can cut rates during a financial crisis. 18

To analyze the effect of cutting early and slow compared to cutting early and late, we fix

\footnotetext{
${ }^{18}$ Models of "information effects" of Fed policy have the same result that cutting once but big is better than small and frequent, see for example Campbell et al. (2019).
} 
$i^{P u t}=0 \%$ and $i^{L A W}=4.5 \%$, and we also set the lower threshold $\eta^{P u t}$ at either $16 \%$ or $0 \%$. When $\eta^{P u t}=16 \%$, rates are held at zero for almost the entire crisis region. When $\eta^{P u t}=0 \%$, rates are always positive converging to zero on at the very worst part of a crisis (if $\eta=0$ ). We then consider how stability varies with $\eta^{L A W}$ : higher $\eta^{L A W}$ corresponds to "early" rate cuts in the sign of financial-sector distress, but shallower rate cuts, while a lower $\eta^{L A W}$ corresponds to "late" but fast rate cuts.

Figure 8 (a) plots stability as a function of $\eta^{L A W}$. How stability varies with $\eta^{L A W}$ depends critically on $\eta^{P u t}$. When $\eta^{P u t}=16 \%$ so that rates will be brought to zero just before a crisis occurs, stability is improved by delaying rate cuts until right before $\eta^{P u t}$ )—but then cutting quickly to zero. As the red line illustrates, stability is greatest when $\eta^{L A W}$ is very close to $\eta^{P u t}$, corresponding to late but fast cuts. In this case, the change in rates is larger, which leads to greater changes in stability in a crisis, allowing more stability globally. Waiting too long, however, will hurt stability (intuition below).

The results are quite different when rates are constrained to be positive during crises. When $\eta^{P u t}=0 \%$, then it is better for stability to cut rates sooner; maximal stability occurs when $\eta^{L A W}$ is around $4.5 \%$, much higher than was true in the previous case. In this case, because rates will not hit zero unless a terrible crisis occurs, cutting rates earlier means lower rates everywhere-in a crisis, and before the crisis. Thus, it's important in this case to begin cutting rates early in order to get rates low enough to provide support for the financial sector.

The intuition is provided in Figure 8(b), which plots how the crisis threshold $\bar{\eta}$ varies with $\eta^{L A W}$ in both cases. The black line depicts when $\eta^{L A W}$ precisely equals the crisis threshold $\bar{\eta}$. When the blue or red line fall below the black line, then policy cuts rates before the crisis. Remember that in the crisis region $\eta<\bar{\eta}$ households hold capital, depressing the returns on bank assets and weakening the automatic stabilizing mechanisms in the economy. When $\eta^{P u t}=16 \%$ so that rates will be held at zero throughout the crisis, waiting to cut rates (lower $\eta^{L A W}$ ) stabilizes the economy, and so in general the size of the crisis region endogenously remains almost the same (the red line $\bar{\eta}$ does not change until $\eta^{P u t}$ is close to $\eta^{L A W}$ ). Keeping the powder dry does not endogenously make the crisis occur sooner in the financial cycle. In contrast, when $\eta^{P u t}=0 \%$ so 


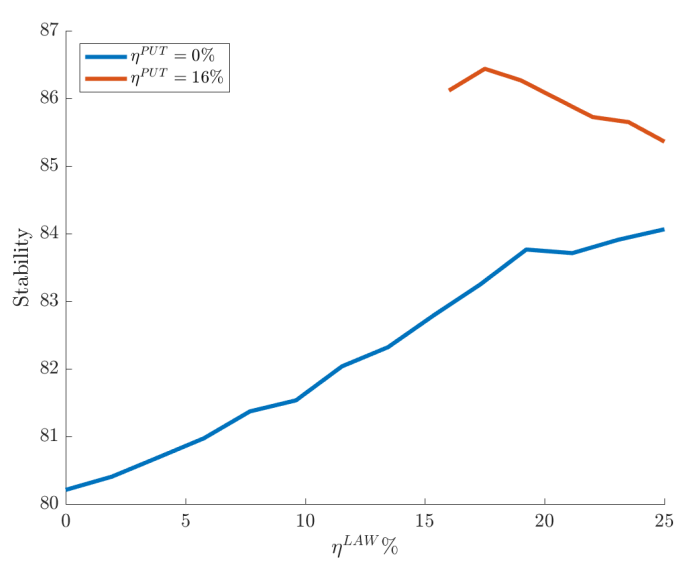

(a) Timing and Stability

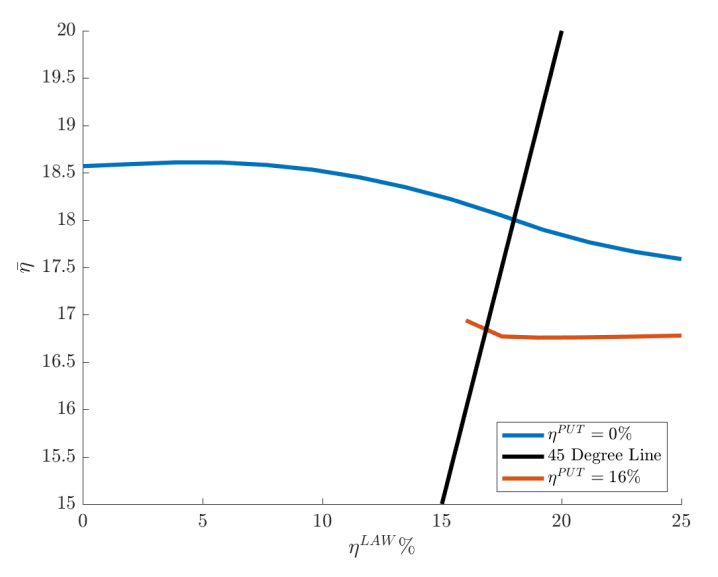

(b) Changes in $\bar{\eta}$

Figure 8: Stability and endogenous changes in the crisis given timing of rate cuts.

that rates are positive in a crisis, the economy is always less stable, and so endogenously the crisis occurs earlier ( $\bar{\eta}$ is always higher for the blue line). Furthermore, when $\eta^{L A W}$ is low so that rates are held high for longer, the crisis occurs even earlier in the cycle, and can even occur while rates are still held at $i^{L A W}$. In this case, waiting to cut makes the crisis more likely, consistent with the intuition that a rate cut would provide "vaccination" against a crisis occurring. The same effect occurs when $\eta^{P u t}=16 \%$ and rates are not cut until the last moment, which is why the red line increases faster when $\eta^{L A W}$ approaches $\eta^{P u t}$.

\section{Additional Results on Monetary Policy and Stability}

\section{D.1 Baseline and Constant Rate Policies}

Asset Prices and Dynamics Figure 9 (a) plots the asset price $Q(\eta)$ under each policy rule. As expected, higher interest rates lead to lower asset prices. The asset price under the Baseline policy is slightly higher than when rates are constant at 4.5\%. A simple heuristic of "higher asset prices means more ex-ante instability" turns out to be wrong. Importantly, even though interest rates are always between $0 \%$ and $4.5 \%$, and even though asset prices are between the levels when rates are at $0 \%$ and $4.5 \%$, the behavior of leverage, volatility, and stability are quite different. 


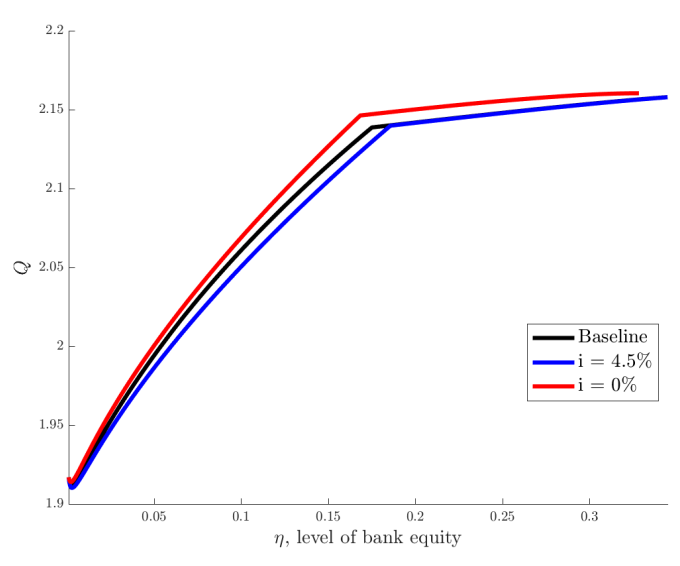

(a) Asset Price
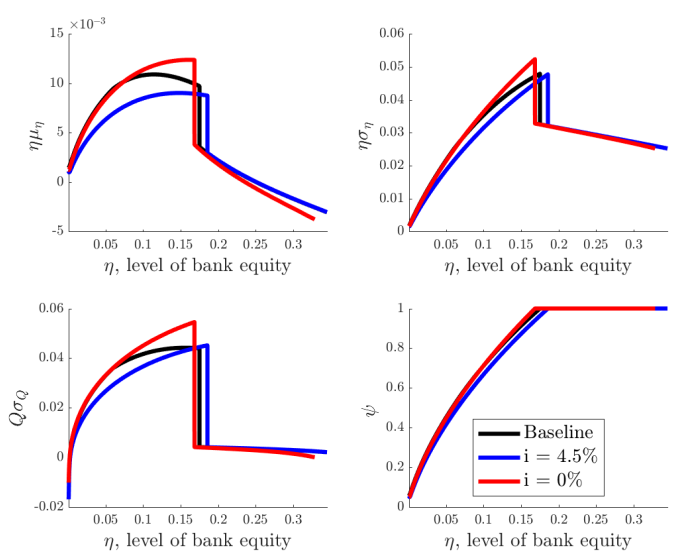

(b) $d \eta, \sigma_{Q}$, and $\psi$

Figure 9: Equilibrium prices and evolutions with constant rates and Baseline policy.

Figure 9 (b) provides further insight into why the Baseline policy generates the most stable economy. This panel plots the equilibrium drift and volatility of $\eta$; volatility of $Q$; and capital allocations $\psi$. The discontinuities in $\mu_{\eta}$ and volatilities occur at $\bar{\eta}$, below which households hold capital (roughly $\eta=17 \%$ in these economies). First, consider the constant rate policies. The volatilities of the asset price and bank equity are higher with low constant interest rates, consistent with the standard intuition that low rates may be destabilizing by increasing volatility. Lower constant rates also increase the drift of bank equity ( $\mu_{\eta}$ is higher), which is consistent with the intuition that low rates allow banks to finance themselves more cheaply and to build up equity. Under the Baseline policy, the drift $\mu_{\eta}$, volatilities, and capital allocations largely fall in between the values under the constant rate rules.

Therefore, the Baseline policy is more stable than the constant rate rules because it combines the benefits of both policies without their downsides. The $i=4.5 \%$ policy is undesirable because it reduces leverage in bad times-precisely when it is needed. The $i=0 \%$ policy is undesirable because it causes volatilities to rise too much and does not generate as high returns for banks in good times. Combining a Fed Put with LAW avoids these downsides while still obtaining the positive effects of these policies. 
Welfare A relevant summary statistic for understanding welfare is the share of household wealth held in their personal net worth $\omega$. For a given $\eta$, the lower $\omega$ is, the more valuable a household's shares in bank equity are. In other words, if households hold less of their wealth in their personal net worth under certain policy rules, then financial intermediation by banks provides relatively more value under those policy rules. Figure 10 confirms that globally higher welfare is associated with globally lower $\omega$ and thus more valuable intermediation by banks.

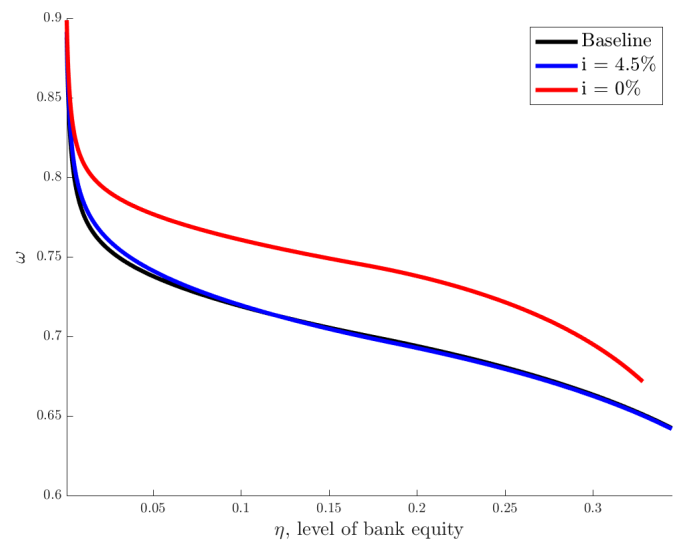

Figure 10: Household welfare via $\omega$ under the Baseline, $i=0 \%$, and $i=4.5 \%$ policies

\section{D.2 State-Dependent Consequences of Monetary Policy}

In this section, we investigate the state-dependency of monetary policy. If $\eta^{P u t}<\eta^{L A W}$, then changing $i^{P u t}$ and $i^{L A W}$ also changes the slope of the interest rate rule for $\eta \in\left[\eta^{P u t}, \eta^{L A W}\right]$. To isolate the Put and LAW components of the policy rule $(15)$, we set $\eta^{P u t}=\eta^{L A W}$ to implement piecewise interest rate rules. A different $i^{P u t}$ or $i^{L A W}$ now only affects the interest rate in the Put or LAW region.

State-Dependent Returns The stabilizing effects of a Put depend on when rates decrease ( $\eta^{\text {Put }}$ ) because the effects of higher or lower interest rates depend on whether rates primarily affect allocations or prices. Recall our discussion about the identity of the marginal investor. When households are the marginal investors in capital (i.e., below $\bar{\eta}$ ), policy changes affect allocations (banks take on 
more leverage when rates decrease) without detrimentally decreasing the returns on banks' assets. In contrast, when banks are the marginal investors in capital (i.e., above $\bar{\eta}$ ), policy changes affect the capital price but not allocations, which influences banks' profitability. To illustrate these points, consider two piecewise rules—one where the policy "strike" is at a lower level of $\eta^{P u t}=12 \%$, inside the crisis region where households hold capital, and another at a higher level of $\eta^{P u t}=25 \%$, outside the crisis region. Figure 11 plots the Sharpe ratios for these two cases along with the Sharpe ratios under constant rates of $0 \%$ and $4.5 \%$.

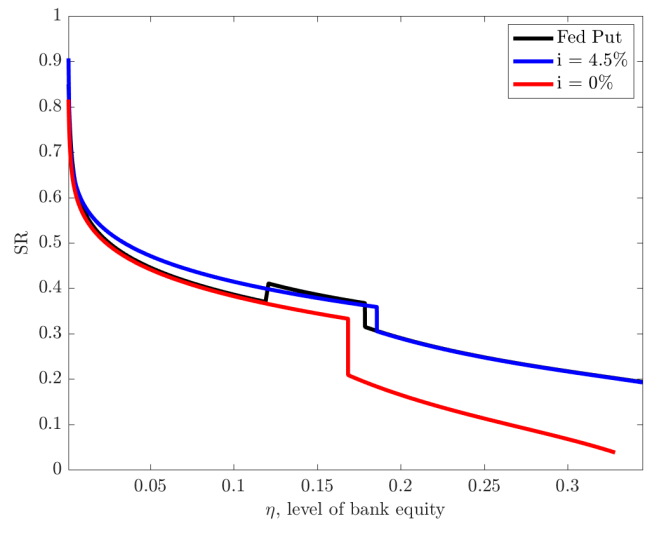

(a) Low strike, $\eta^{P u t}=12 \%$

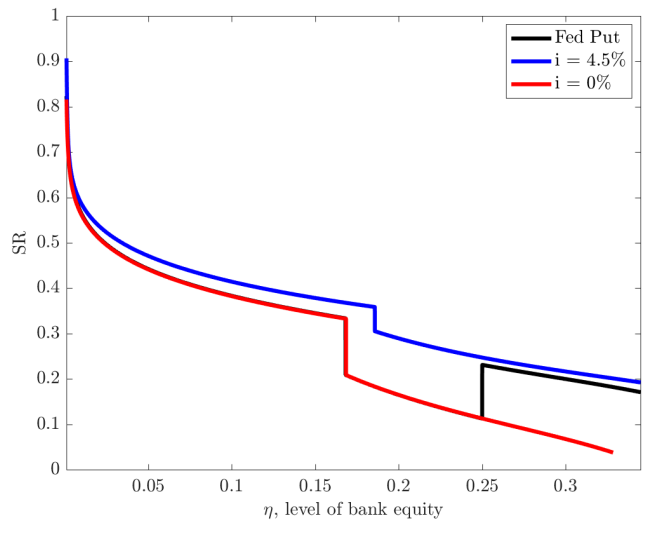

(b) High strike, $\eta^{\text {Put }}=25 \%$

Figure 11: Sharpe ratios varying the policy strike for piecewise Put.

The Sharpe ratio under the Put with low strike $\eta^{P u t}=12 \%$ (Figure 11(a)) is higher than the other policies when $\psi$ initially falls below 1 . This behavior is the most effective for stabilizing the economy because it reduces the probability that the economy slips from a minor recession into a severe one. The high returns in good times further stabilizes the economy by keeping banks wellcapitalized. However, the Sharpe ratio under the Put with a high strike (Figure 11(b)) is essentially the same as the $i=0 \%$ policy except for very high $\eta$. Even then, the Sharpe falls below the one when $i=4.5 \%$ always. This behavior reflects the fact that cutting rates in good times passes through to prices rather than allocations, which depresses banks' returns and thus profitability.

To understand the intuition for our results, it is also helpful to consider two extreme benchmarks for how monetary policy could pass through into "prices and quantities" (or "returns and leverage"). In a frictionless economy, a decrease in nominal rates would decrease the nominal 
return on banks' investments exactly one-for-one so that the profitability of banking would not change. There would be no change in banks' leverage, banks' rate of equity growth, or volatility. In contrast, if a decrease in nominal rates did not pass through perfectly to returns, then the profitability of banking would increase, banks would increase their leverage, and banks' rate of equity growth would increase. In our model, changes in monetary policy when banks are well-capitalized affect bank returns, with no effect on bank leverage because banks are the marginal investors in capital. Decreasing banks' funding costs (cutting rates) when banks have very low levels of capital increases banks' excess returns and encourages banks to use more leverage, enabling banks to rebuild equity more quickly.

Unconditional LAW When we only consider policies with constant (unconditional) rates, lower constant interest rates improve stability. Even though lower rates produce higher asset price volatility globally, low rates also allow banks to rebuild equity quickly, so capital is better allocated in the long run. These results with constant interest rates provide a strong argument against unconditionally leaning against the wind. Globally higher rates do not mitigate excessive risk-taking enough to offset the losses from inefficient capital allocations arising when the banking sector is distressed.

State-Contingent Easing and Leaning Against the Wind Constant low interest rates lead to a more stable distribution but higher volatility, but a state-dependent policy can achieve both stability objectives: high interest rates (at times) to generate low volatility, and low interest rates (at other times) to generate a favorable stationary distribution. Leaning against the wind must be statecontingent. The global behavior of leverage depends on the state-dependent behavior of interest rates much more than on the overall level. We now consider timing considerations regarding when to lean against the wind and when to ease. Like the previous section, we consider piecewise rules to isolate the Put and LAW components of the policy rule.

First, cutting rates in bad times is stabilizing, as is raising rates in good times. We find that LAW generally improves stability when the central bank raises rates outside of crises. We solve the model with $i^{L A W} \in[0,5 \%]$ and $i^{P u t} \in[0,3 \%]$. Figure 12 plots stability for $\eta^{P u t}=3 \%$ and $18 \%$. Two results emerge clearly. A more aggressive Fed Put (lower $i^{P u t}$ ) is always more stabilizing 
regardless of the level of $i^{L A W}$, and the position of the policy strike matters. When $\eta^{P u t}$ is outside the crisis region, then a higher $i^{L A W}$ is more stabilizing-LAW in good times is an effective policy. However, if $\eta^{P u t}$ is so low that rates are high for most of a crisis, a higher $i^{L A W}$ leads to a less stable economy, as is the case when $\eta^{P u t}=3 \%$ (Figure 12 (a)).

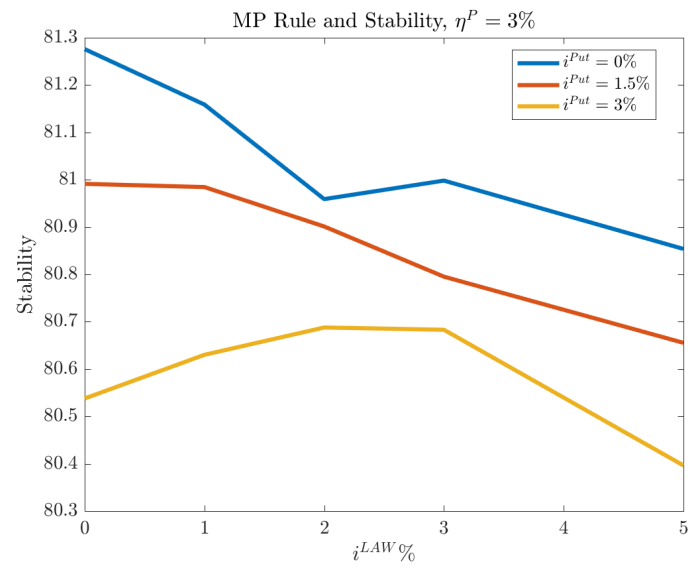

(a) $\eta^{P u t}=3 \%$

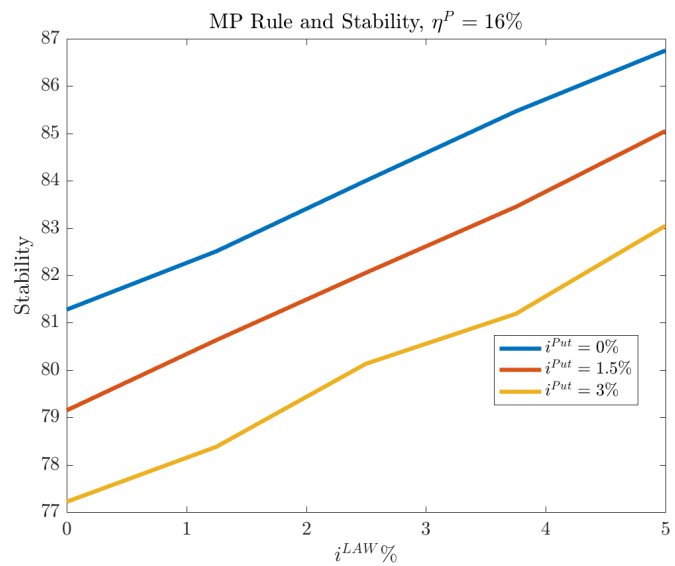

(b) $\eta^{\text {Put }}=18 \%$

Figure 12: Stability with Leaning against the Wind together with a Fed Put, varying $\left(i^{L A W}, i^{P u t}\right)$ and varying $\eta^{P u t}$.

Since higher $i^{L A W}$ implies higher interest rates on average, it is instructive to compare the LAW/Put policy to a constant-rate policy with the interest rate set equal to the long-run average rate $\mathbb{E}[i]$ under the LAW/Put policy. We fix $i^{P u t}=0 \%$ and vary $i^{L A W}$. We compute the average interest rate $\mathbb{E}[i]$ under the piecewise policy and then compare stability under the piecewise policy to stability under the constant-rate policy with the same level of average rates. While in an absolute sense LAW may or may not improve stability ( see $\eta^{P u t}=3 \%$ ), LAW always leads to stability gains compared to the constant-rate policy, and those gains are larger for higher $i^{L A W}$.

The evidence of this section suggests that LAW in good times can be an effective policy toward improving financial stability. Increasing interest rates has a detrimental effect on stability when higher rates increase bank funding costs during crises, precisely when increasing bank equity is most valuable, and precisely when changing funding costs has minimal effect on banks' investment returns. A carefully targeted policy of leaning against the wind in good times, and only in good 
times, can improve financial stability. ${ }^{19}$

\section{D.3 Poorly Targeted Macroprudential Policy}

Some research (e.g. Phelan, 2016) has found that binding leverage constraints in bad times can improve stability and welfare. On the other hand, the real problem may be excessive leverage when signs of financial distress begin to appear. Tightening constraints before distress turns into a crisis may improve outcomes by accepting some output losses today to avoid more severe economic damage. Figure 13 illustrates these policies as linearly decreasing leverage constraints which bind in one of three different regions of the state space. The "Crisis" leverage constraint binds only when $\eta$ is low, and the "Distress" leverage constraint binds when banks still intermediate a large fraction of capital.

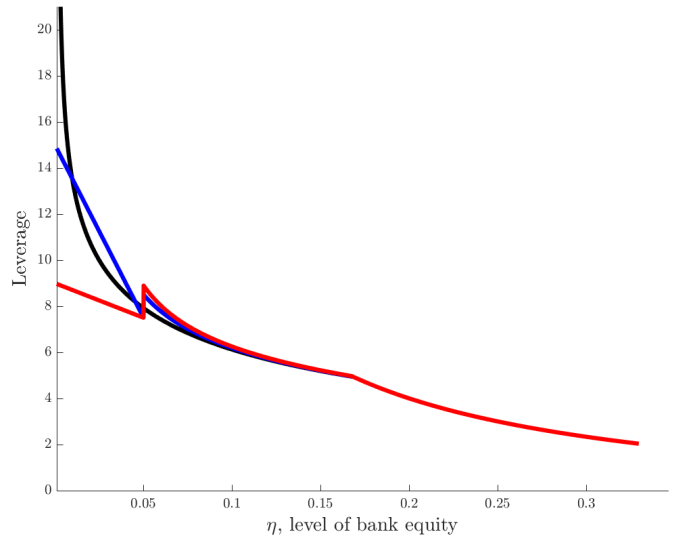

(a) Crisis

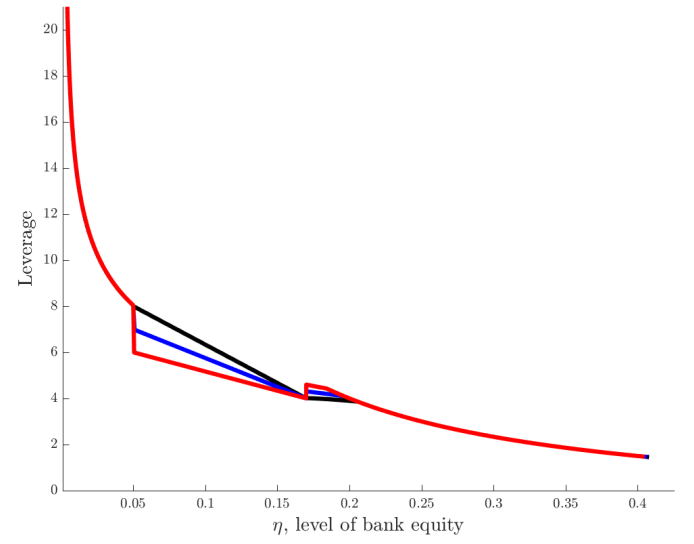

(b) Distress

Figure 13: Linearly decreasing leverage constraints that bind only in one of two regiones, Crisis or Distress. The black lines correspond to the loosest constraints. The leverage constraint corresponding to the blue lines are tighter than the black ones, and the red lines are the tightest. In all cases, the nominal interest rate follows the Baseline policy.

Leverage constraints during the Crisis and Distress phases of the financial cycle turn out to be poorly targeted and thus fail to restrict leverage when it is most socially suboptimal. For both types

\footnotetext{
${ }^{19}$ While endogenous instability, represented either by $\sigma^{Q}$ or $\sigma^{\eta}$, is highest for moderate values of $\eta$, excessive risk taking in terms of the effect on stability is highest for high $\eta$. This is evident from the behavior of $\sigma^{Q}$ in Figure 1 . A policy that raises interest rates for middle values of $\eta$ does not improve stability and generally harms stability.
} 
of macroprudential policies, a Fed Put with LAW still improve household welfare and outperforms constant rate rules. Tables 4 and 5 show the consumption equivalent welfare differences and stability differences between alternative interest rate rules and the Baseline policy. The Baseline policy always outperform constant rate rules (e.g. $i=0 \%$, average conditional interest rate), and rules with more aggresive Put or LAW improve welfare and stability. However, the Distress policy does improve household welfare relative to the case of no leverage constraints, which suggests that the Distress policy mitigates excessive risk taking but could be better targeted.

Table 4: This table lists welfare and stability under the Crisis and Distress leverage constraint policies. The black, blue, and red lines in Figure 13 correspond to the "Loosest", "Moderate", and "Tightest" labels in the first column. The columns consider alternative constant rate rules. Welfare is reported first in consumption equivalent differences from the Baseline policy, and stability is reported second in percentage point differences from the Baseline policy.

\begin{tabular}{lccc}
\hline \hline Leverage Constraint & $i=0 \%$ & $i=4.5 \%$ & $\mathbb{E}[i]$ \\
\hline & & & \\
Crisis & & & \\
Tightest & & & \\
Moderate & $(-3.20 \%,-3.55 \%)$ & $(-4.52 \%,-4.54 \%)$ & $(-4.36 \%,-4.63 \%)$ \\
Loosest & $(-3.33 \%,-3.43 \%)$ & $(-5.13 \%,-4.19 \%)$ & $(-4.85 \%,-4.06 \%)$ \\
& $(-3.15 \%,-3.49 \%)$ & $(-4.36 \%,-4.56 \%)$ & $(-4.38 \%,-4.30 \%)$ \\
Distress & & & \\
Tightest & & & \\
Moderate & & & \\
Loosest & $(-0.88 \%,-2.34 \%)$ & $(-4.72 \%,-3.68 \%)$ & $(-3.75 \%,-3.58 \%)$ \\
& $(-0.75 \%,-4.12 \%)$ & $(-4.36 \%,-4.84 \%)$ & $(-4.11 \%,-4.95 \%)$ \\
\hline \hline
\end{tabular}


Table 5: This table lists welfare and stability under the Crisis and Distress leverage constraint policies. The black, blue, and red lines in Figure 13 correspond to the "Loosest", "Moderate", and "Tightest" labels in the first column. The columns consider the effects of different $i^{L A W}$ and $i^{P u t}$ values. Welfare and stability are reported as an ordered pair. Welfare is reported first in consumption equivalent differences from the Baseline policy, and stability is reported second in percentage point differences from the Baseline policy.

\begin{tabular}{lccc}
\hline \hline Leverage Constraint & $i^{L A W}=5.5 \%$ & $i^{L A W}=3.5 \%$ & $i^{P u t}=1 \%$ \\
\hline & & & \\
Crisis & & & \\
Tightest & & & \\
Moderate & $(0.67 \%, 0.98 \%)$ & $(-0.68 \%,-0.88 \%)$ & $(-0.68 \%,-0.81 \%)$ \\
Loosest & $(0.57 \%, 1.07 \%)$ & $(-0.84 \%,-0.67 \%)$ & $(-0.93 \%,-0.92 \%)$ \\
& $(0.67 \%, 0.98 \%)$ & $(-0.74 \%,-0.95 \%)$ & $(-0.83 \%,-0.82 \%)$ \\
Distress & & & \\
Tightest & & & \\
Moderate & $(0.12 \%, 1.26 \%)$ & $(-0.31 \%,-0.26 \%)$ & $(-0.75 \%,-0.45 \%)$ \\
Loosest & $(0.17 \%, 0.41 \%)$ & $(-0.22 \%,-1.43 \%)$ & $(-0.79 \%,-0.36 \%)$ \\
& $(0.22 \%, 3.03 \%)$ & $(-0.27 \%,-1.92 \%)$ & $(-0.63 \%,-0.29 \%)$ \\
\hline \hline
\end{tabular}

